\title{
Application of Spectral and Wavelet Analysis of Stator Current to Detect Angular Misalignment in PMSM Drive Systems
}

Research Article

\author{
Przemysław Pietrzak ${ }^{\circledR}$, Marcin Wolkiewicz* \\ Wrocław University of Science and Technology, Wybrzeże Wyspiańskiego 27, 50-370 Wrocław, Poland
}

Received: April 07, 2021; Accepted: May 04, 2021

\begin{abstract}
This paper deals with the selected methods of detecting angular misalignment in drive systems with a permanent magnet synchronous motor (PMSM), which are based on the analysis of the stator phase current signal, as well as their experimental verification and comparison. The proposed and compared methods are spectral analysis and wavelet analysis of the stator current, stator current envelope, stator current space vector module. Furthermore, the influence of power supply frequency and load torque on the performance of the proposed diagnostic methods is also discussed. The experimental tests were carried out for an undamaged motor and for two levels of angular misalignment. The article discusses the question of exactly what damage symptoms can be extracted from each of the methods. In the case of spectral analyses, it is demonstrated which multiplicities of the failure frequency are the most sensitive to misalignment and the least sensitive to changes in motor operating condition, which may be considered novel in the case of drive systems with permanent magnet motors. It is also proven that discrete wavelet transform (DWT) of the envelope and monitoring of the value of the relevant components allows the detection of misalignment with the availability of measuring current only in one phase in various motor operating conditions.
\end{abstract}

Keywords: fault diagnosis • permanent magnet synchronous motor • angular misalignment • fast Fourier transform • discrete wavelet transform

\section{Introduction}

High efficiency, wide range of speed control, high power density and many other advantages have made the permanent magnet synchronous motors (PMSMs) to be used more often in drive systems (Usman et al. 2017). Despite their many advantages, they may be damaged electrically, magnetically or mechanically (Wang et al. 2018). Motor failure may result in stopping of industrial processes leading to large financial losses, which is why fault diagnostics and condition monitoring are becoming more and more popular and important (Tarchala et al. 2020).

Mechanical damages can be divided into bearing damage, rotor unbalance, eccentricity and misalignment (Ewert and Musial, 2017). Misalignment may be caused, among others, by inaccurate assembly of parts (such as motors), temperature rise of the machine structure, improper alignment of motor coupling, quantity of grease inside of the coupling guard, cyclic fatigue and forces transmitted to supporting elements (Piotrowski, 1995). Furthermore, incorrect alignment also has a negative effect on couplings, shafts and bearings. Misalignments may also affect the useful life of machines and even destroy the drive system. Additionally, in the case of experimental tests, misalignment may cause measurement errors of the dynamic properties of the drive systems (Liu et al. 2014).

Misalignment is a condition wherever the centrelines of coupled shafts do not coincide. In general, there are two types of misalignment: parallel and angular (Behera et al. 2014). These types are shown in Figure 1. Systems used for drive alignment prior to commissioning have been available in the market for many years. Nevertheless, misalignment can also occur during drive system operation; so, it is essential to monitor the alignment online. 
A

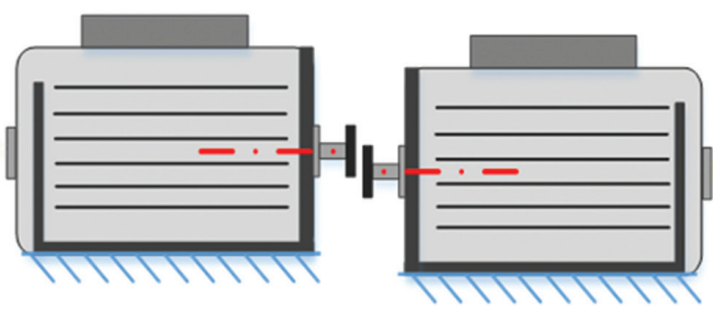

B

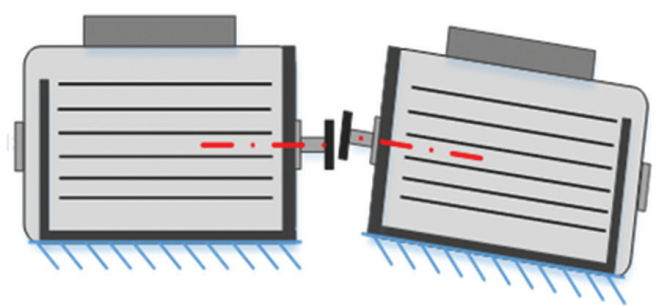

Fig. 1. Misalignment types (a) parallel, (b) angular.

Methods of detecting misalignment are mainly based on the non-invasive measurement of mechanical vibrations and stator phase current (Chacon et. al. 2014; Verma et. al. 2014). In most cases, spectral analysis of these signals and the extraction of characteristic fault frequencies are used. Such solutions in the literature have been discussed mainly for drive systems with induction motors (Antonino-Daviu and Popaleny, 2018; Thomson and Culbert, 2017; Raj et. al. 2013). Moreover, the use of a discrete wavelet transform (DWT) of vibration signal to detect misalignment is also proposed in the literature for this type of drive systems (Saputra et al. 2019a; Umbrajkaar and Krishnamoorthy 2018).

Despite the fact that the misalignment of induction motor and synchronous motor with permanent magnets causes the same type of failure, due to the specific features of PMSM, it is worth paying attention to the methods of detecting this type of failure in these motors, because the fault symptoms may be different than in the case of induction motor.

In this paper, the applicability of stator current Root Mean Square (RMS) value monitoring, spectral and wavelet analysis of stator current, stator current envelope and stator current space vector module to detect angular misalignment in drive systems with PMSM are presented and assessed. The so-far unexplored influence of the load torque and the frequency of the supply voltage on the values of symptoms distinguished with the use of these methods were also discussed.

\section{Symptoms of Misalignment in the Stator Phase Current Signal}

In the fault diagnosis of electric motors, the most frequently used signal is the stator phase current (Kim, 2011). Some of the diagnostic methods are based on a raw current signal (Hang et. al. 2016). With this approach, signal parameters such as amplitude, RMS value and kurtosis may be monitored. Nevertheless, most of them rely on processed signals using a variety of mathematical apparatuses.

In the case of the spectral analysis of the stator phase current signal with the fast Fourier transform (FFT), the symptom of a failure may be an increase in the characteristic frequency components. According to the theory, in case of misalignment, the fault frequency components are described by Eq. (1) (Bossio et. al. 2009):

$$
f_{s} \pm k f_{r}
$$

where $f_{s}$ - power supply frequency $[\mathrm{Hz}], k$ - positive integer $(1,2,3, \ldots)$ and $f_{r}$ - rotational frequency.

The $f_{r}$, rotational frequency, is calculated according to Eq. (2) $[\mathrm{Hz}]$

$$
f_{r}=\frac{n}{60}
$$

Where $n$ - rotation speed [rpm].

The appearance of additional frequency components due to angular misalignment causes current fluctuations that may be visible in the signal envelope, which can be determined using the Hilbert transform according to Eq. (3):

$$
i_{s}^{H}(t)=\sqrt{i_{s}^{2}(t)+H^{2}\left[i_{s}(t)\right]}
$$


where $H\left[\mathrm{i}_{\mathrm{s}}(\mathrm{t})\right]$ is the Hilbert transform of the stator phase current signal and it is expressed as (Zhang et. al. 2016)

$$
H\left[i_{s}(t)\right]=\frac{1}{\pi} \int_{-\infty}^{+\infty} \frac{i_{s}(t)}{t-\tau} d \tau
$$

The frequency components of the stator phase current envelope spectrum specific to misalignment are:

$$
k f_{r} \text {. }
$$

Theoretically, symptoms of misalignment can also be found in the spectrum of the stator phase current space vector module, which is calculated according to Eq. (6):

$$
\left|i_{s}\right|=\sqrt{i_{s \alpha}^{2}+i_{s \beta}^{2}}
$$

where $i_{s a}, i_{s \beta}-$ components of a stator phase current space vector module in the stationary reference frame ( $\left.\alpha-\beta\right)$.

The $\alpha-\beta$ components of the stator current space vector are related to the stator phase currents with dependencies resulting from the Clark transform:

$$
\begin{aligned}
& i_{s \alpha}=\frac{2}{3} i_{s A}-\frac{1}{3} i_{s B}-\frac{1}{3} i_{s C} \\
& i_{s \beta}=\frac{1}{\sqrt{3}} i_{s B}-\frac{1}{\sqrt{3}} i_{S C}
\end{aligned}
$$

where $i_{S A}, i_{S B}, i_{s C}-$ stator currents in the phase A, B and C.

Phase current space vector components can also carry information about the state of the motor. The change in the shape of the hodograph of the stator phase currents in $\alpha-\beta$ coordinates may be the evidence of damage to the motor. On the other hand, in the case of the stator phase current space vector module spectral analysis, the same frequency components as for the stator phase current envelope spectral analysis may increase due to misalignment - Eq.(5) (Ewert and Musial, 2017). The characteristic failure frequencies for each approach are grouped in Table 1.

The DWT can be particularly useful for detecting this type of fault (Saputra et al. 2019b). It allows the decomposition of diagnostic signals to the frequency range in which diagnostic information is contained. DWT performs multi-resolution wavelet analysis. At each of its stages, the signal can be split into two components. To obtain these components, a set of filters (low- and high-pass) and the signal sampling operation are used, selecting only even samples (Olkkonen, 2011).

The practical form of DWT in numerical calculations is expressed:

$$
D W T_{j, k}(t)=\sum_{n=0}^{N-1} x(n) \psi_{j k}^{*}(n)
$$

Table 1. List of characteristic failure frequencies occurring in the FFT spectra of individual diagnostic signals based on the stator phase current.

\begin{tabular}{lll}
\hline Diagnostic signal & Failure frequencies & Comments \\
\hline \hline Stator phase current & $f_{s} \pm k f_{r}$ & $f_{s}$ - power supply frequency, \\
Stator phase current envelope & $k f_{r}$ & $f_{r}$ - rotational frequency, \\
Stator current space vector module & $k f_{r}$ & $k$ - positive integer $(1,2,3, \ldots)$. \\
\hline
\end{tabular}

FFT, fast Fourier transform. 
where $\psi_{j k}^{*}(n)$ is the conjugation of a function of the form:

$$
\psi_{j, k}(n)=2^{-\frac{j}{2}} \psi\left(2^{-j} n-k\right)
$$

where $N$ - number of samples determined by the limits of occurrence of the wavelet described by Eq. (10).

In this method, a symptom of failure may be a change in the approximations and details, the frequency band of which covers the characteristic failure frequencies.

\section{Experimental Setup}

The motor used in the research was a PMSM with a rated power of $2.5 \mathrm{~kW}$ powered by a voltage source inverter. The laboratory stand and schematic diagram of the experimental setup are shown in Figure 2. Multi-range transducers were used to measure the stator phase currents of the tested PMSM LEM LA 25-NP. The control structure was implemented on a rapid prototyping system using the National Instruments (NI) PXI system. The output signals from the transducers were entered into the DAQ NI-PXI 4492 measurement card by NI. Owing to the capabilities of the laboratory stand, the impact of the angular misalignment on the drive system operation was analysed. To model the angular misalignment, the tested motor was lifted in the z-axis as shown in Figure 3. Three cases were investigated - first coaxially with the second $4.7 \mathrm{~kW}$ PMSM acting as a load (misalignment Level 0), second lift equal to $2 \mathrm{~mm}$ (misalignment Level 1) and third $-5 \mathrm{~mm}$ (misalignment Level 2). This corresponded to a slope of $0^{\circ}, 0.367^{\circ}$ and $0.909^{\circ}$, respectively. It was supposed to correspond to undamaged drive system, a small angular misalignment and a large angular misalignment. These motors were connected via a backlash-free, torsionally fastened, maintenance-free clutch with a steel plate connector (KTR-RADEX NC 35).

\section{Analysis of Experimental Results of the Proposed Methods of Detecting Angular Misalignment}

The experimental verification of the proposed methods of detecting angular misalignment in drive systems with PMSMs was carried out for various values of load torque $T_{L}-(0 \div 1) T_{N}$ with a step of $0.2 T_{N}$ and the frequency of the

A

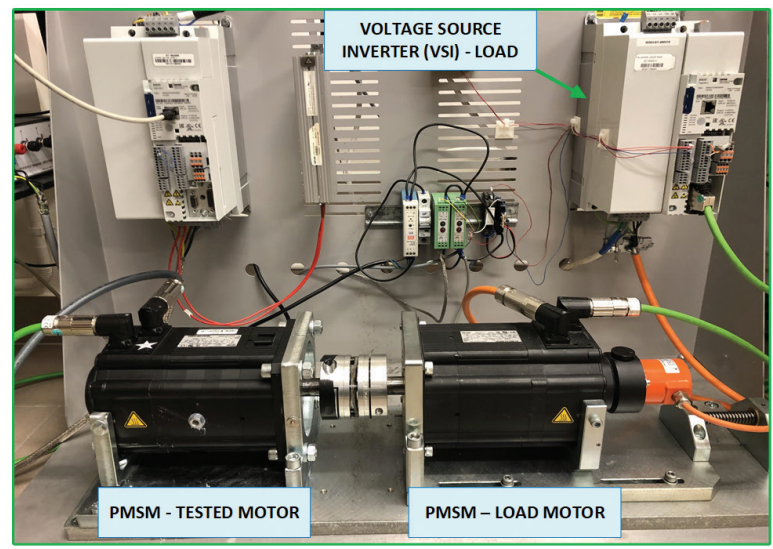

B

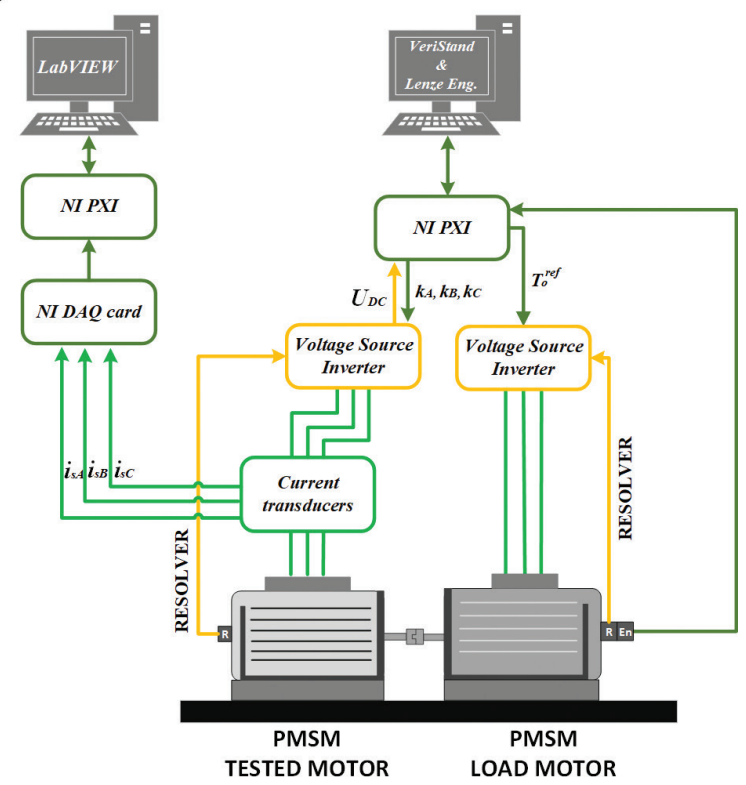

Fig. 2. (a) Photo of the laboratory stand, (b) general scheme of the experimental setup. 


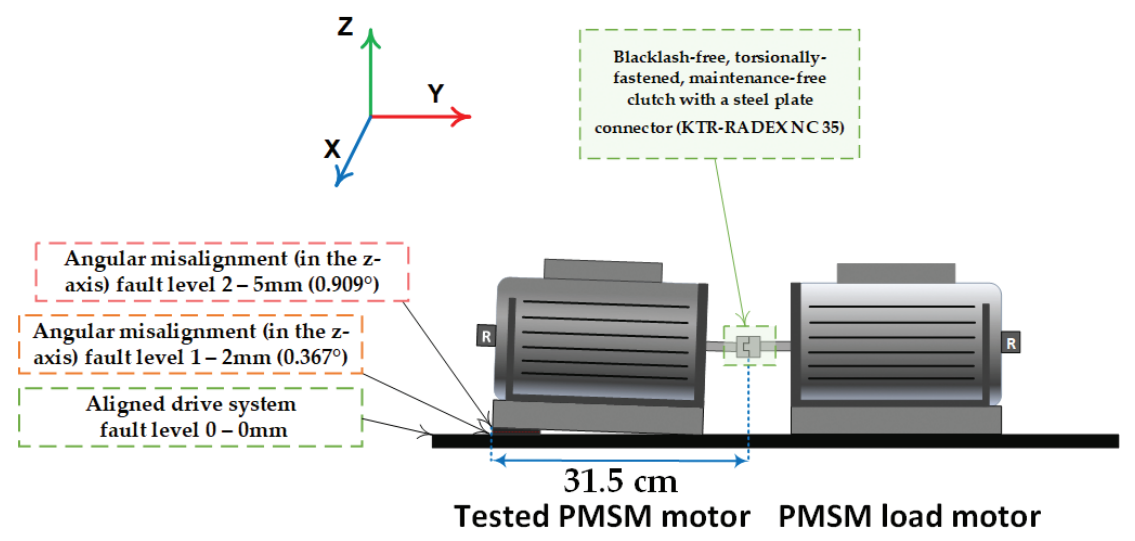

Fig. 3. A method of modelling angular misalignment.

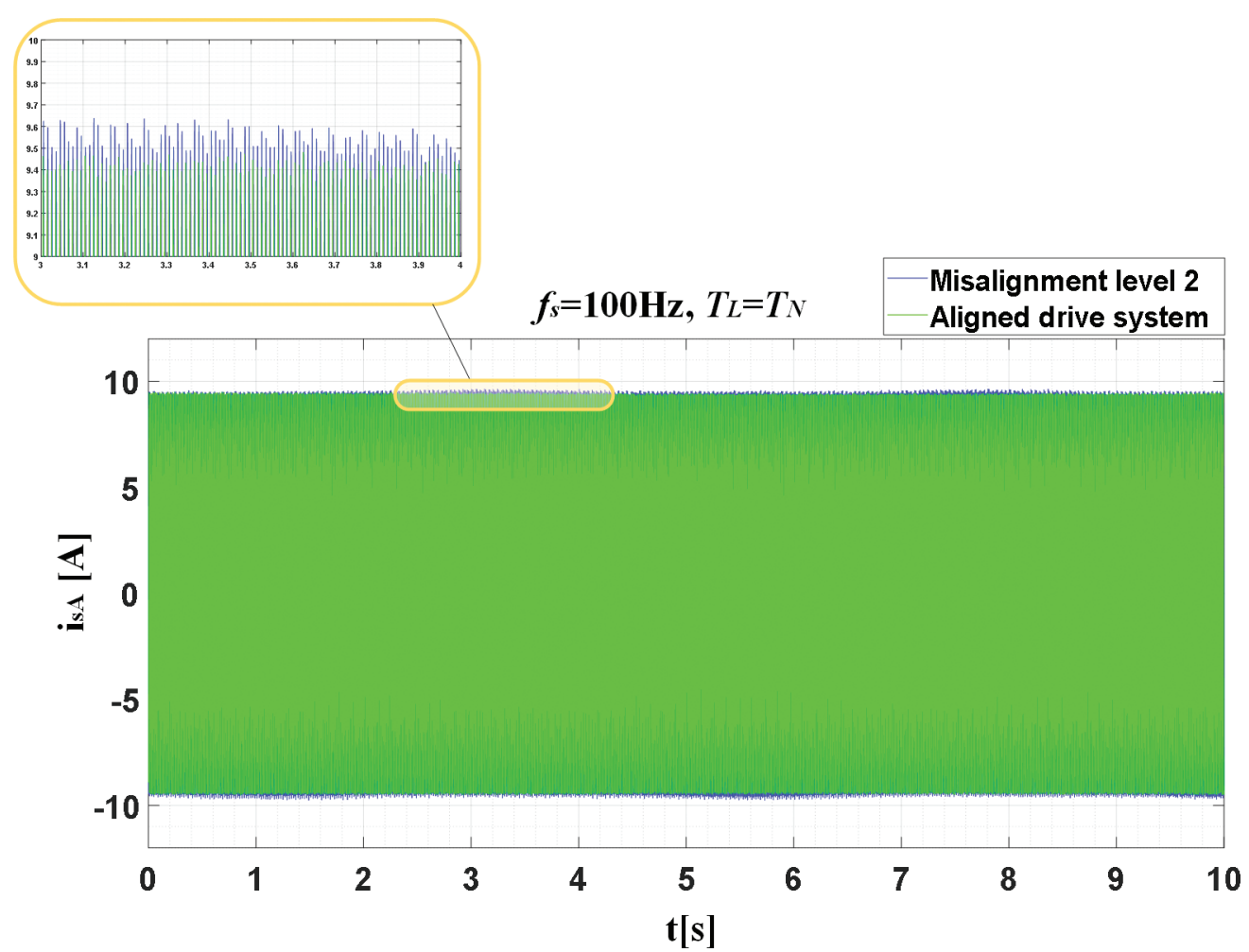

Fig. 4. The stator current waveforms of phase $A$ for the $P M S M$ operating at $f_{S}=100 \mathrm{~Hz}$ and $T_{L}=T_{N}$, for the aligned drive system and with misalignment Level 2 (5 mm). PMSM, permanent magnet synchronous motor.

supply voltage (rotational speeds) $-(50 \mathrm{~Hz} \div 100 \mathrm{~Hz})$ with a step of $10 \mathrm{~Hz}$, when the rated frequency was $100 \mathrm{~Hz}$. It corresponded to $1,500 \mathrm{rpm}$. This allowed to examine the influence of motor operating conditions on the values of fault symptoms and to select those which are the least sensitive to them.

\subsection{Analysis of changes in the RMS value of the stator phase current}

The electric motor fault may change the parameters of the stator phase current signal, such as amplitude and RMS values. The waveforms of the stator phase currents without misalignment and with the misalignment of Level 2 are shown in Figure 4. Comparing these waveforms, an increase in the amplitude of the phase current can be seen after the angular misalignment of the drive system occurs. To analyse these changes, the RMS values were compared for different $T_{L}$ and levels of misalignment (Figure 5). On their basis, it can be concluded that the misalignment 


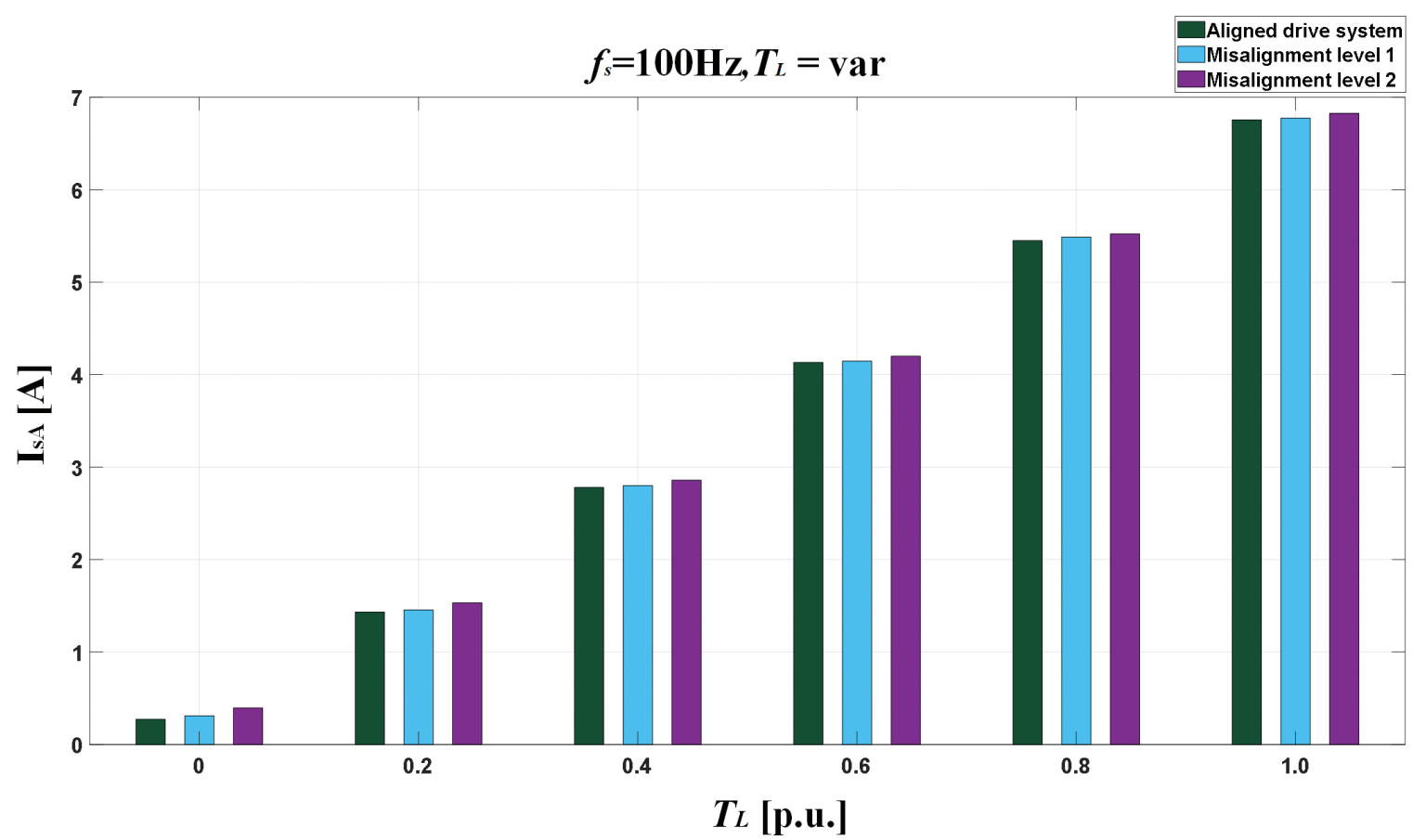

Fig. 5. The stator current RMS values of phase $A$ for the PMSM operating at $f_{s}=100 \mathrm{~Hz}$ and various load torque for the aligned drive system with misalignment Level $1(2 \mathrm{~mm})$ and Level $2(5 \mathrm{~mm})$. PMSM, permanent magnet synchronous motor; RMS, root mean square.

causes an increase in the RMS current value. However, this value also depends on the load torque; so, it is not good and insensitive to a change in motor operating condition fault indicator.

\subsection{Spectral analysis using the fast Fourier transform}

\subsubsection{Spectral analysis of the stator current signal}

The FFT allows for the extraction of characteristic failure frequencies in the signal amplitude spectrum. In the case of stator current signal and misalignment faults, these may be the frequencies described by Eq.(1). In Figure $6(a$ and $b)$, the phase current spectrums of the phase A for a motor coaxial to the loading machine and for two levels of angular misalignment are presented, operating without and at rated load torque and rated rotation speed. In these spectrums a significant increase in the values of the frequency components described by Eq.(1) for $k$-values equal to 1 after the occurrence of angular misalignment can be seen. The influence of the load torque, power supply frequency and misalignment level on the values of these components is shown in Figure 6(c-f).

Based on the presented analysis, it can be concluded that the greatest increases after the occurrence of angular misalignment are in the fs-fr and fs-fr components. Importantly, the impact of the load torque on the values of these components is relatively small. In the case of the power supply frequency changes, the components are the least dependent on its changes are fs-fr and fs+fr. Nevertheless, the influence of the fs changes on the value of these symptoms is visible.

\subsubsection{Spectral analysis of the stator current signal envelope}

The envelope of the stator phase current was calculated in accordance with Eq.(3). In Figure 7(a and b), the phase A current envelope spectrums for a motor coaxial to the loading machine and for two levels of angular misalignment are shown. In these spectrums, an increase in the values of frequency components described by Eq.(4) for $k$-values equal to 1 and 2 after the occurrence of angular misalignment can be observed. The influence of the load torque and misalignment level on the values of these components is shown in Figure $7(\mathrm{c}, \mathrm{d})$. On the other hand, the influence of the power supply frequency is presented in Figure 7(e, f).

Based on the surface plots shown in Figure 8(c-f), it can be concluded that the $f_{r}$ component is very sensitive to misalignment and does not depend on the load torque, which makes it a very good fault indicator. Additionally, this 
A

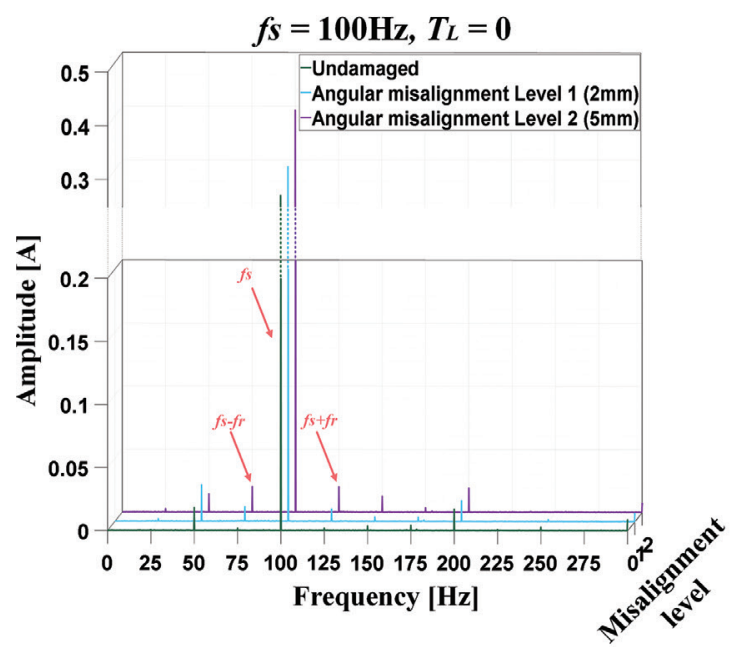

C
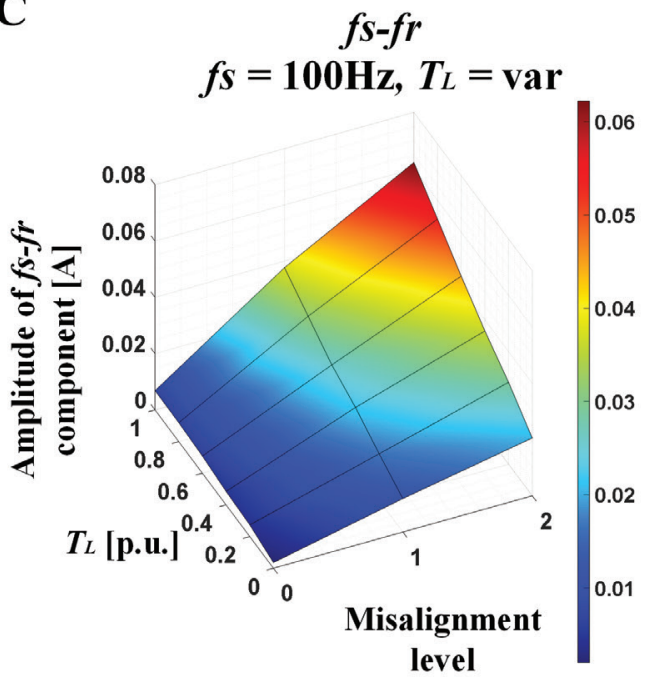

E

$$
\begin{gathered}
f s-f r \\
f s=\operatorname{var}, T_{L}=T_{N}
\end{gathered}
$$

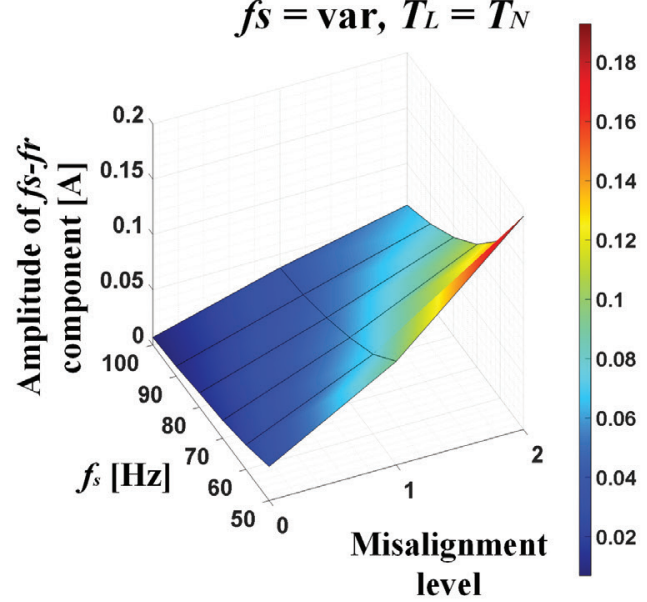

B

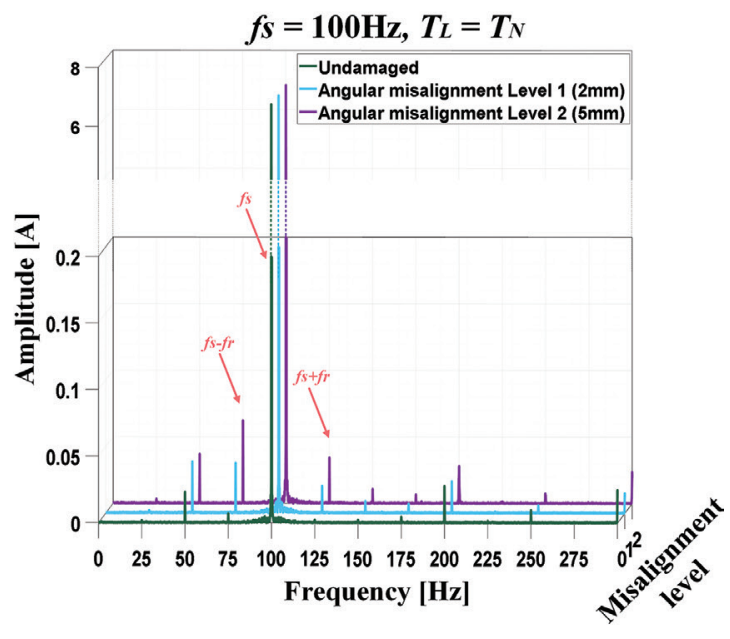

D

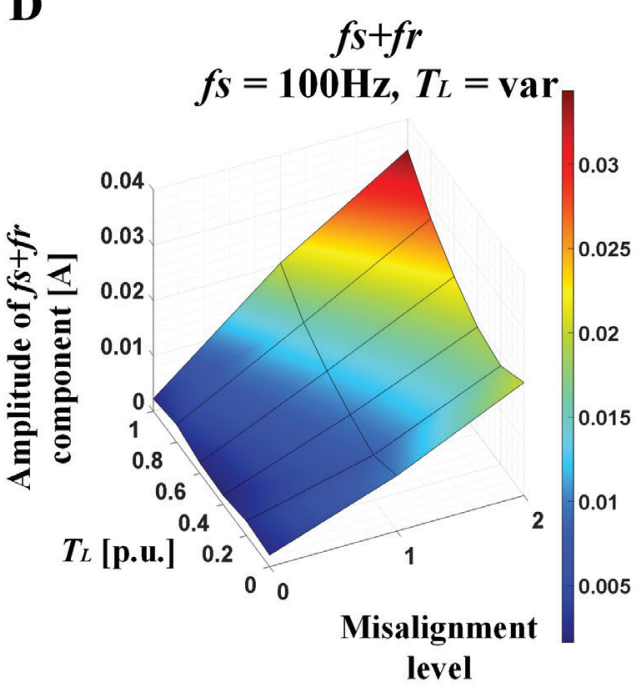

F

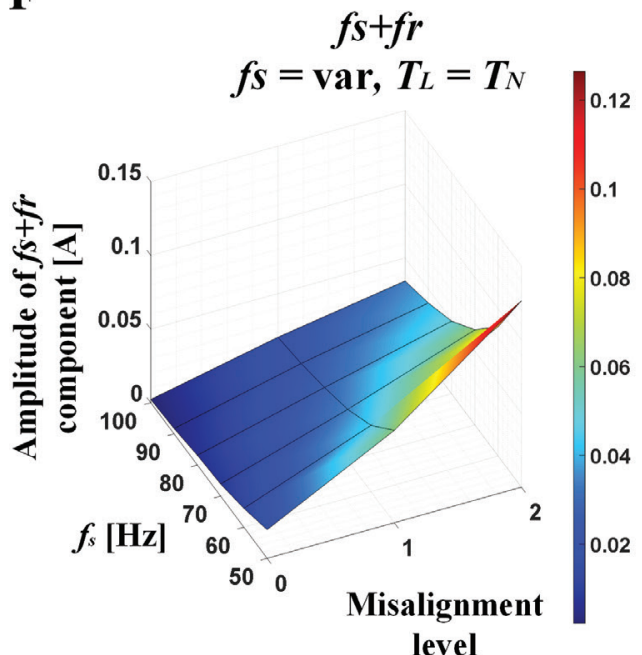

Fig. 6. (a, b) Stator phase current spectrum $\left(f_{s}=100 \mathrm{~Hz}, T_{L}=0, T_{L}=T_{N}\right),(\mathrm{c}, \mathrm{d})$ values of characteristic failure frequencies $\left(f_{s}=100 \mathrm{~Hz}, T_{L}=\right.$ var), $(e, f)$ values of characteristic failure frequencies $\left(f_{s}=\right.$ var, $\left.T_{L}=T_{N}\right)$ for the motor coaxial to the loading machine and for two levels of angular misalignment. 


\section{A}

$f s=100 H z, T_{L}=0$

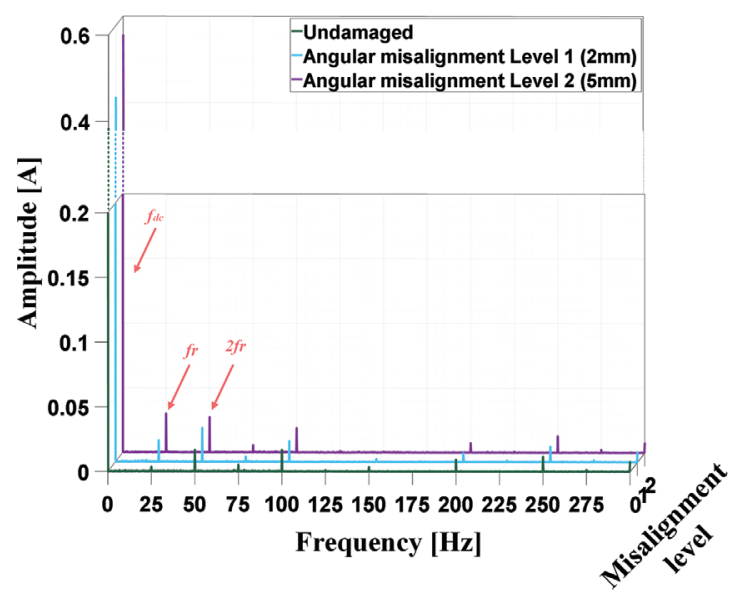

C

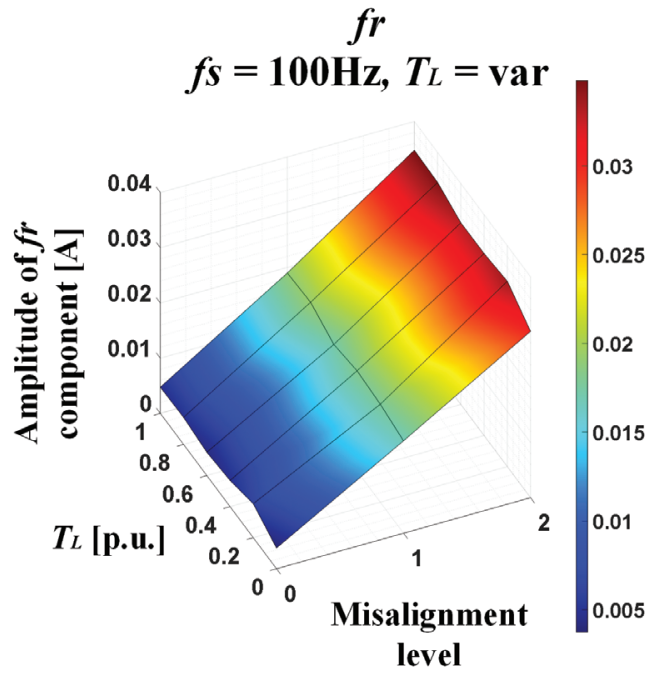

$\mathbf{E}$

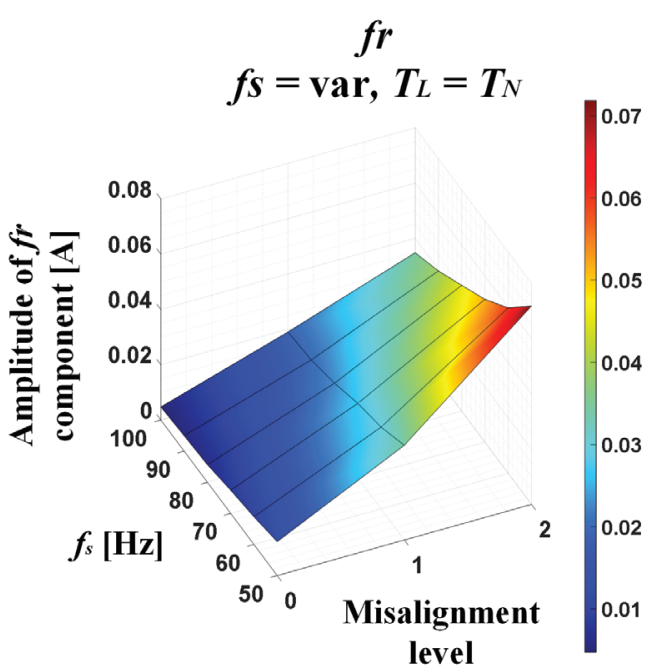

B

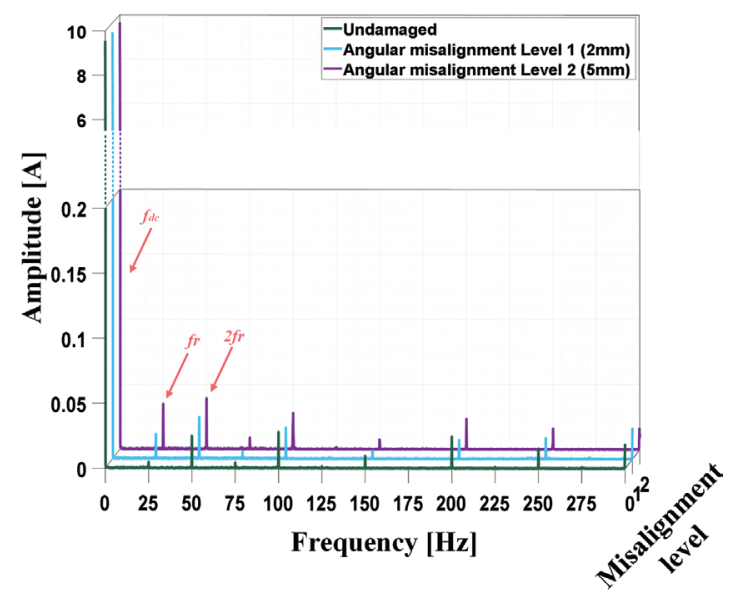

D

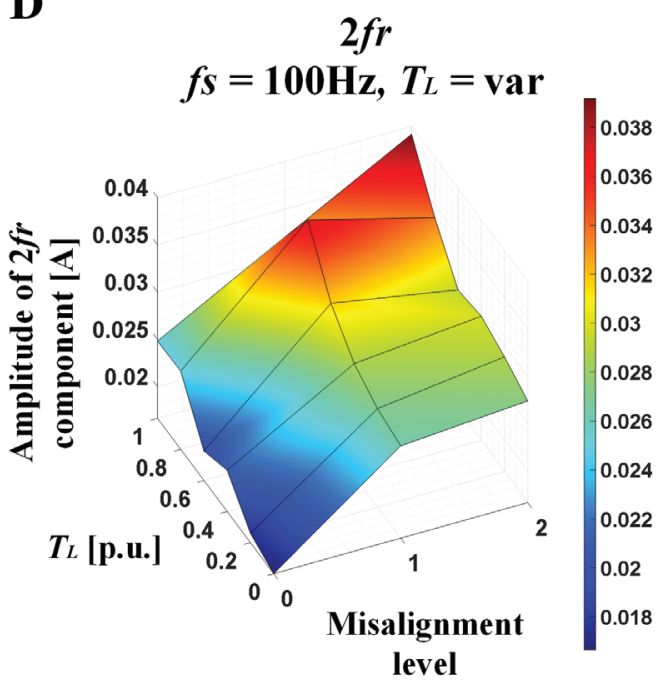

$\mathbf{F}$

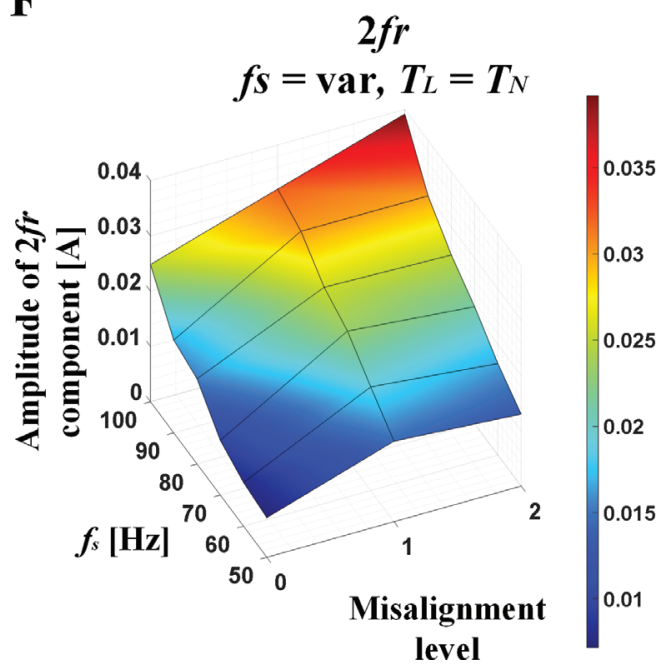

Fig. 7. (a, b) Stator phase current envelope spectrum $\left(f_{s}=100 \mathrm{~Hz}, T_{L}=0, T_{L}=T_{N}\right),(\mathrm{c}, \mathrm{d})$ values of characteristic failure frequencies $\left(f_{\mathrm{s}}=100 \mathrm{~Hz}\right.$, $T_{L}=$ var), (e, f) values of characteristic failure frequencies $\left(f_{S}=\operatorname{var}, T_{L}=T_{N}\right)$ for the motor coaxial to the loading machine and for two levels of angular misalignment. 
component depends less on the frequency of the supply voltage compared to the symptoms visible in the spectrum of the stator phase current.

\subsubsection{Spectral analysis of the stator current space vector module}

The stator phase current space vector components may also carry information about the state of the motor. The stator phase current hodographs for the unloaded motor and operating at the rated load torque and various degrees of misalignment are shown in Figure 8. Based on the observations of these hodographs, it can be concluded that the angular misalignment causes a change in the trajectory of the hodograph. The absolute value of this change for the selected part of the hodograph is marked on the hodograph. These changes occur both for the unloaded motor and for the motor operating at rated load torque. The disadvantage in using hodographs in fault detection is the requirement for human (expert) interpretation in the final evaluation of the degree of hodograph deformation (misalignment detection). Therefore, it is worth using stator current space vector module spectral analysis, and not only its components to the inference about the motor state.

Determining the space vector module of the stator phase current makes it possible to filter the frequency components from the FFT spectrum that hinder the diagnosis of faults, such as the frequency component of the power supply. In the case of misalignment, the fault symptom may be frequencies described by Eq. (5).

In Figure 9(a, b), the stator phase current space vector module spectrums for a motor coaxial to the loading PMSM and for two levels of angular misalignment are shown. As in the case of the stator current envelope spectrum, in these spectrums a notable increase in the values of frequency components described by Eq.(5) for $k$-values equal to 1 and $2\left(f_{r}, 2 f_{r}\right)$ after the occurrence of angular misalignment can be observed. The influence of the load torque and misalignment level on the values of these components is shown in Figure 9(c, d), whereas the influence of the power supply frequency is presented in Figure $9(e, f)$.

It follows from these graphs that the rotational frequency component $\left(f_{r}\right)$ is highly sensitive to misalignment and does not depend on the load torque, which makes it very useful to the fault diagnosis and drive system alignment monitoring.

A

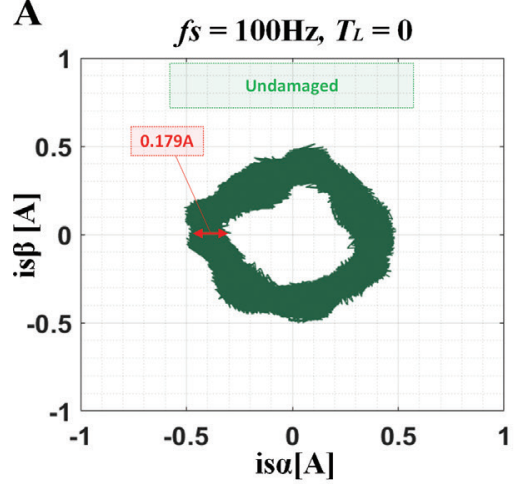

D

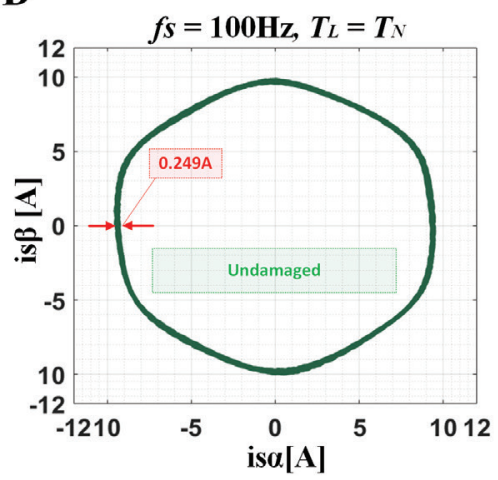

B

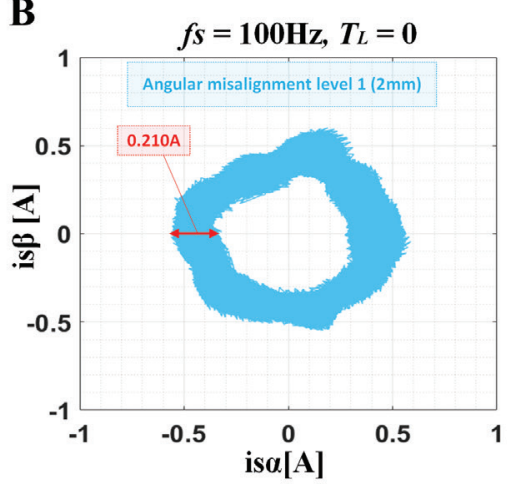

$\mathbf{E}$

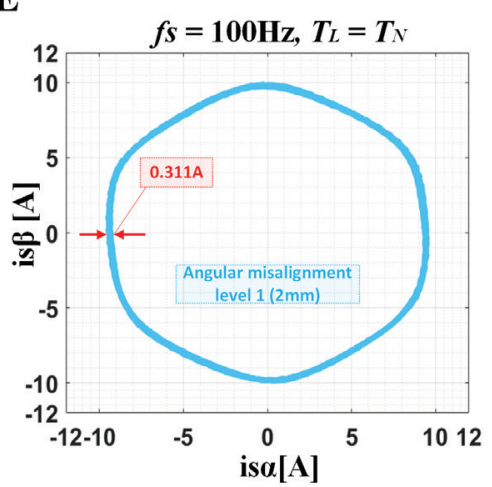

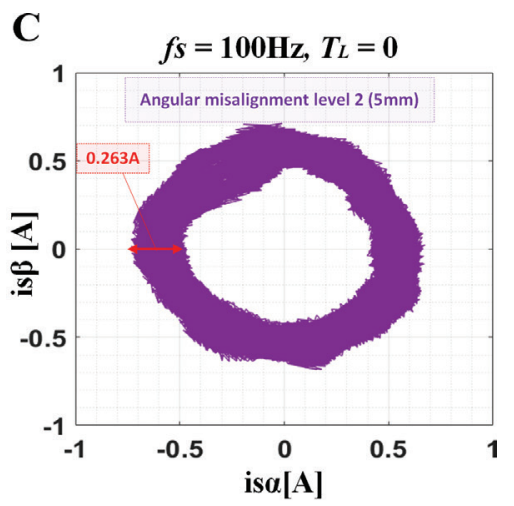

F

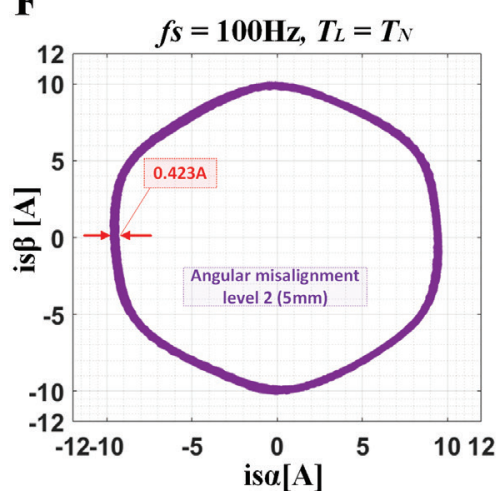

Fig. 8. Influence of angular misalignment on the shape of the current hodograph working at rated frequency $\left(f_{s}=100 \mathrm{~Hz}\right)$ and $(\mathrm{a}-\mathrm{C})$ without load, $(\mathrm{d}-\mathrm{f})$ with rated load torque. 
A

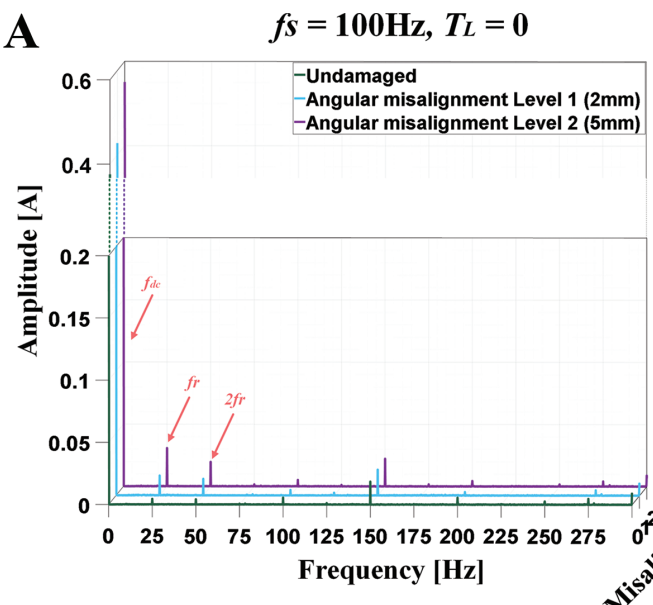

C

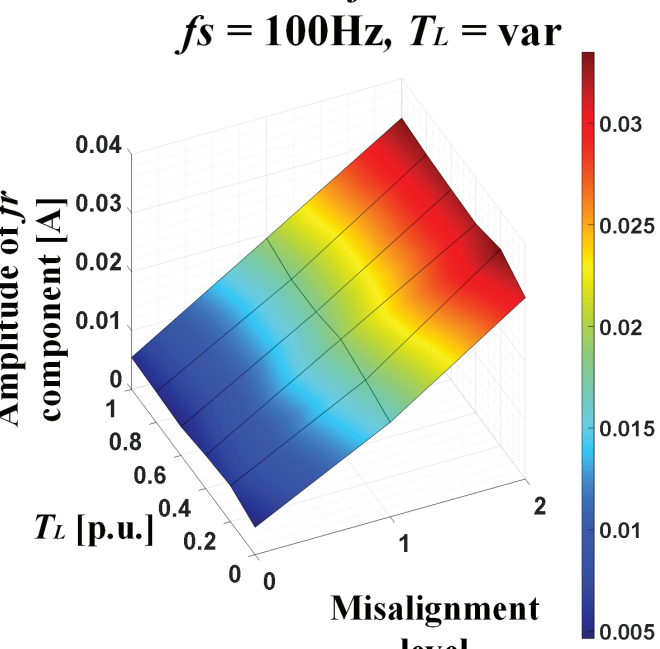

level

$\mathbf{E}$

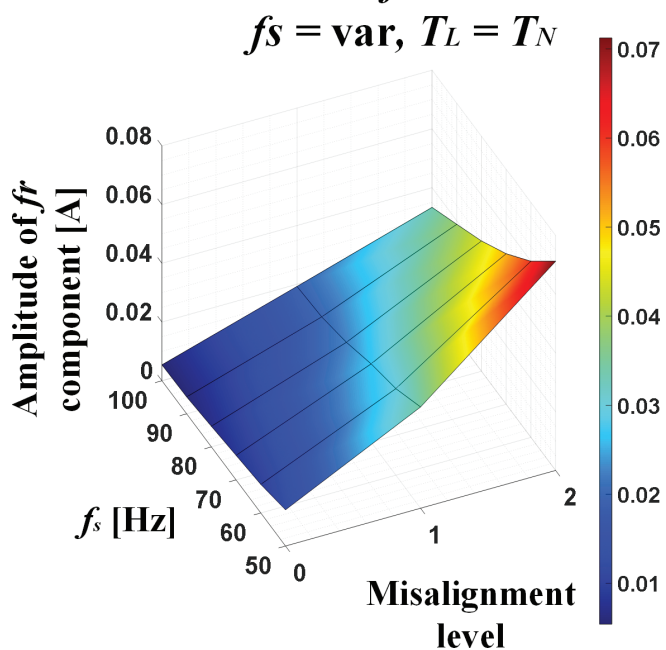

B

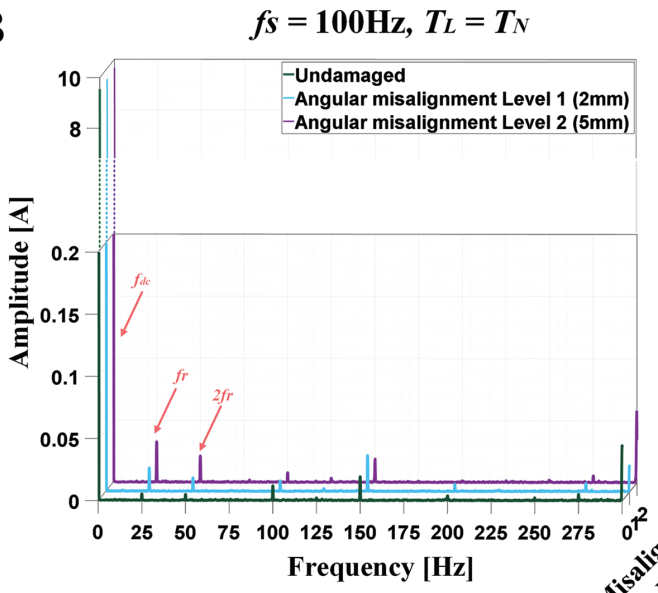

D

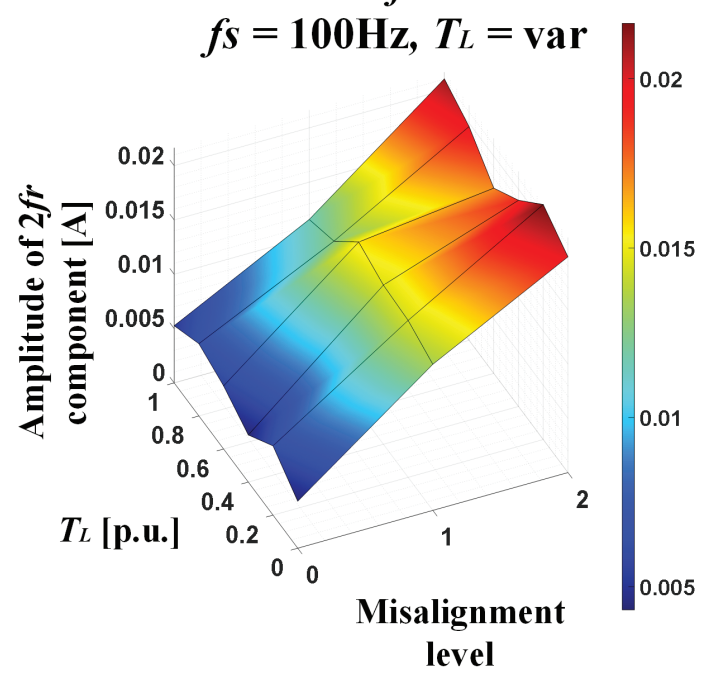

$\mathbf{F}$

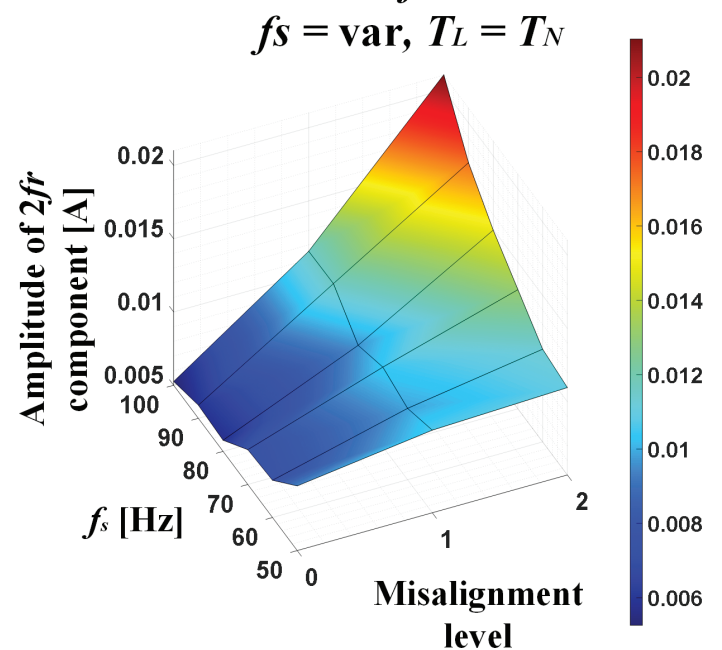

Fig. 9. (a, b) Stator phase current space vector module spectrum $\left(f_{s}=100 \mathrm{~Hz}, T_{L}=0, T_{L}=T_{N}\right)$, (c, d) values of characteristic failure frequencies $\left(f_{s}=100 \mathrm{~Hz}, T_{L}=v a r\right),(\mathrm{e}, \mathrm{f})$ values of characteristic failure frequencies $\left(f_{\mathrm{s}}=\mathrm{var}, T_{L}=T_{N}\right)$ for the motor coaxial to the loading machine and for two levels of angular misalignment. 


\section{Summary}

Based on the spectral analyses of the selected diagnostic signals presented above, it can be concluded that they can be successfully used to detect misalignment in drive systems with PMSMs. Nevertheless, each of these methods is characterised by different effectiveness and sensitivity to changes in the load torque and frequency of the supply voltage.

Table 2 lists the amplitude values of the failure frequency components that are most sensitive to misalignment for each of the discussed signal spectrums. Additionally, ratios of values for a given level of misalignment to values for aligned drive system are given in parentheses; these have been calculated according to Eq. (11). A calculation example is shown in Eq. (12). On the basis of these values, it can be stated that the greatest increases occur for the frequency component $f_{s}+f_{r}$, but the values of these frequency components strongly depend on the load torque and the power supply frequency, as presented earlier. Therefore, from the point of view of diagnostics and monitoring of the drive system alignment, it seems much better to use the spectral analysis of the stator phase current envelope or the stator current module and to monitor the value of the $f_{r}$ component amplitudes, because it depends less on the motor operating conditions than in the case of the $f_{s}+f_{r}$ in the stator phase current spectrum, with a large increase at the same time after the occurrence of misalignment - an increase of about $400 \%$ for angular misalignment of Level 1 and about $700 \%$ for Level 2 . Slightly greater increases occur for the $f_{r}$ component in the current envelope spectrum compared to the $f_{r}$ component in the stator current space vector module.

$$
\begin{aligned}
& (\text { Ratio })=\frac{A f_{\text {component for } L \text { misalignment } l v l}}{A f_{\text {component for misalignment } l v l=0}} \\
& (\text { Ratio })_{T_{L}=T_{N}}=\frac{A(f s+f r)_{l v l=2}}{A(f s+f r)_{l v l=0}}=\frac{0.0344}{0.0022}=15.63
\end{aligned}
$$

where $A f_{\text {component for } L \text { misalignment } V I}$ - the amplitude of the characteristic fault frequency in the spectrum of a given signal at the misalignment of the $L$-level $(L=\{0,1,2\}), A f_{\text {component for misalignment } N=0}$ - the amplitude of the characteristic fault frequency in the spectrum of a given signal for the aligned drive system.

To compare the impact of the load torque on the values of the described failure frequency amplitudes, the standard deviation for the entire tested load torque range was calculated according to Eq. (13). These results,

Table 2. The amplitude values of the failure frequency components for each of the discussed signal spectrums and ratios of values for a given level of misalignment to values for aligned drive system in parentheses

\begin{tabular}{lccc}
\hline & Stator phase current spectrum & Stator phase current envelope spectrum & Stator phase current space vector module spectrum \\
\hline \hline Misalignment level & $f_{s}+f_{r}$ & $f_{r}$ & $f_{r}$ \\
$T_{L}=0$ & & & \\
$0(0 \mathrm{~mm})$ & $0.0021(1.00)$ & $0.0038(1.00)$ & $0.0047(1.00)$ \\
$1(2 \mathrm{~mm})$ & $0.0100(4.78)$ & $0.0167(4.45)$ & $0.0161(3.46)$ \\
$2(5 \mathrm{~mm})$ & $0.0204(9.75)$ & $0.0301(8.02)$ & $0.0309(6.64)$ \\
$T_{L}=0.6 T_{N}$ & & & \\
$0(0 \mathrm{~mm})$ & $0.0019(1.00)$ & $0.0042(1.00)$ & $0.0049(1.00)$ \\
$1(2 \mathrm{~mm})$ & $0.0121(6.31)$ & $0.0173(4.11)$ & $0.0180(3.68)$ \\
$2(5 \mathrm{~mm})$ & $0.0227(11.90)$ & $0.0329(7.82)$ & $0.0324(6.63)$ \\
$T_{L}=T_{N}$ & & & $0.0054(1.00)$ \\
$0(0 \mathrm{~mm})$ & $0.0022(1.00)$ & $0.0047(1.00)$ & $0.0193(3.55)$ \\
$1(2 \mathrm{~mm})$ & $0.0203(9.10)$ & $0.0190(4.01)$ & $0.333(6.14)$ \\
$2(5 \mathrm{~mm})$ & $0.0344(15.63)$ & $0.0348(7.34)$ & \\
\hline
\end{tabular}


Table 3. Standard deviation values of the failure frequencies amplitudes for the entire tested load torque range and the ratio of its values for motor operation at rated load and without load (Misalignment level 2-5 mm)

\begin{tabular}{|c|c|c|c|}
\hline & $\begin{array}{l}\text { Stator phase current } \\
\text { spectrum }\end{array}$ & $\begin{array}{c}\text { Stator phase current envelope } \\
\text { spectrum }\end{array}$ & $\begin{array}{l}\text { Stator phase current space } \\
\text { vector module spectrum }\end{array}$ \\
\hline & $f_{s}+f_{r}$ & $f_{r}$ & $f_{r}$ \\
\hline$S$ & 0.0062 & 0.0017 & 0.0009 \\
\hline$\frac{A f_{\text {component for misalignment } \operatorname{lv} 12}\left(T_{L}=T_{N}\right)}{A f_{\text {component for misalignment } \operatorname{lv} 2}\left(T_{L}=0\right)}$ & 1.6827 & 1.1547 & 1.0789 \\
\hline
\end{tabular}

together with the ratio of the failure frequency amplitude value at rated load to the value without load, are grouped in Table 3.

$$
\begin{aligned}
& S=\sqrt{\frac{1}{N-1} \sum_{n=1}^{N}\left|A f_{\text {component for L misalignment lvl }}(n)-\mu\right|^{2}} \\
& \mu=\frac{1}{N} \sum_{n=1}^{N} A f_{\text {component for L misalignment lvl }}(n)
\end{aligned}
$$

On the basis of the results grouped in Table 3, it can be concluded that the $f_{r}$ frequency component amplitude in the stator phase current space vector module spectrum is the least load-dependent fault symptom.

\subsection{Wavelet analysis using the DWT}

\subsubsection{DWT of the stator phase current signal}

To find a symptom of misalignment, which will be even less dependent on the load torque and frequency of the supply voltage, an attempt to use the DWT of the stator phase current, stator phase current envelope and stator current space vector module was made.

First, the analysed signals were re-sampled to obtain a spectrum in the 0-1,024 Hz band. In the case of the stator phase current envelope and space vector module, the $f_{D C}$ component was filtered out. In the next step, signal decomposition to the 5th level was performed (Figure 10). The choice of the decomposition level is based on the values of the characteristic failure frequencies in the FFT spectrums of the methods proposed earlier.

A comparison of approximation and details waveforms for an aligned drive system and angular misalignment (Level 2-5 mm), for the rated power supply frequency $\left(f_{s}=100 \mathrm{~Hz}\right)$ and load torque, is shown in Figure 11. It can be observed that in the case of the misalignment, there is a slight increase in the values of the details number 4 and 5 , the band of which covers the value of the $f_{r}+f_{r}$ component in the spectrum of the stator current space vector module. However, this change is not significant, mainly due to the fact that in the ranges of these frequencies bands there can also be an influence of the $f_{s}$ component with a large amplitude; therefore it is not a good method in terms of the effectiveness of detecting misalignment.

As a misalignment index for the analysis the RMS value of individual details, calculated in accordance with Eq. (15), was adopted.

$$
\left|i_{S}\right|_{R M S}=\sqrt{\frac{1}{n} \sum_{n=0}^{n-1} \| i_{S}|(n)|^{2}}
$$

where $n$ - number of samples for the waveform of each detail and approximation.

The influence of the load torque and misalignment level on the RMS values of details number 4 and 5 is shown in Figure 12(a, b). Moreover, the influence of the power supply frequency is presented in Figure 12(c, d). These 
$A \uparrow$

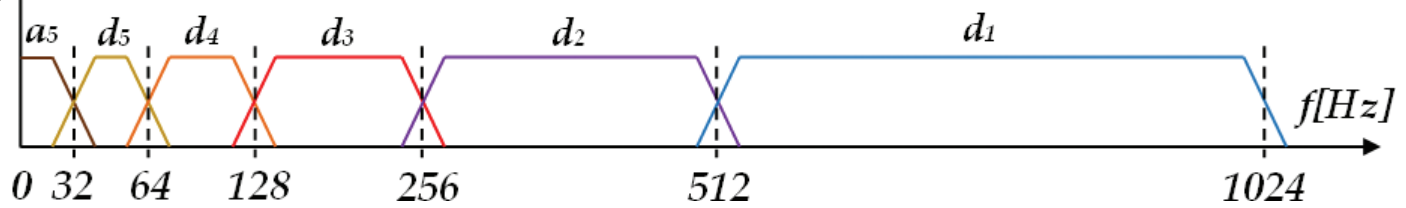

Fig. 10. Frequency bands corresponding to the 5-level decomposition of the oversampled signal of the stator phase current space vector module.

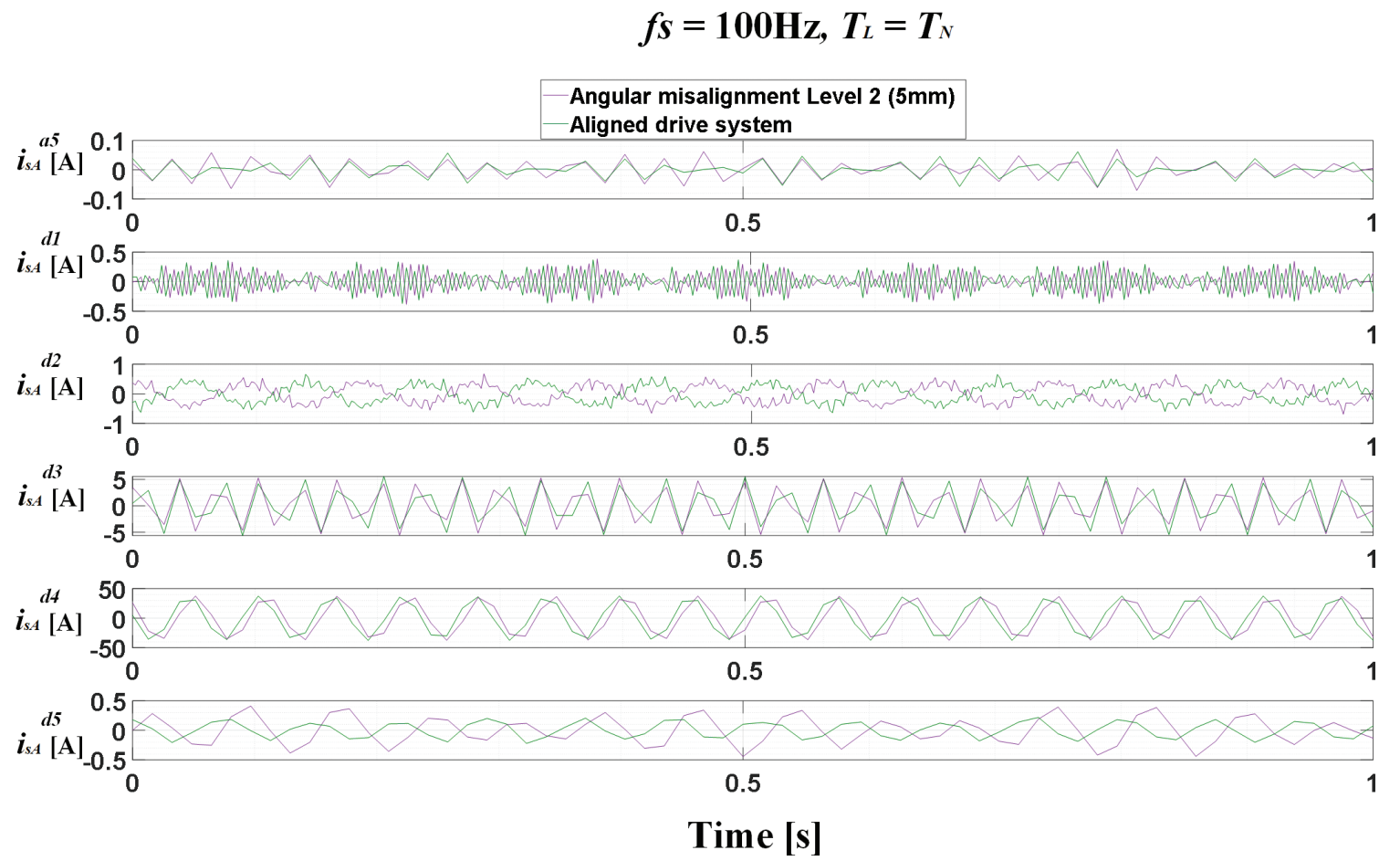

Fig. 11. Waveforms of approximation and details of the DWT of the stator phase current for an aligned drive system and angular misalignment, operating at rated power supply frequency $\left(f_{s}=100 \mathrm{~Hz}\right)$ and with rated load torque. DWT, discrete wavelet transform.

graphs show that these values are strongly dependent on the load and frequency of the supply voltage, which confirms their uselessness in detecting misalignment.

\subsubsection{DWT of the stator phase current envelope}

Subsequently, the possibility of using the DWT of the stator phase current envelope to detect misalignment was investigated. A comparison of approximation and details waveforms for an aligned drive system and angular misalignment (Level $2-5 \mathrm{~mm}$, discussed earlier), for the rated power supply frequency $\left(f_{s}=100 \mathrm{~Hz}\right.$ ) load torque is shown in Figure 13. It can be clearly seen that in the case of misalignment, there is a tremendous increase in the values of the detail and approximation number 5 , the band of which covers the value of the $f_{r}$ component in the spectrum of the stator current envelope. The influence of the load torque and misalignment level on the RMS values of approximation and detail number 5 is shown in Figure 14(a, b), when the influence of the power supply frequency is presented in Figure 14(c, d). It follows from these graphs that the RMS value of the approximation Level 5 - a5 significantly increases with increasing angular misalignment in the entire range of tested frequencies of the supply voltage and the load torque.

\subsubsection{DWT of the stator phase current space vector module}

The possibility of applying the DWT of the stator phase current vector module was analysed as the last one. A comparison of approximation and details waveforms for the same conditions as for DWT of current envelope is shown in Figure 15. In this case, there is also a significant increase in the values of the detail and approximation 
Pietrzak and Wolkiewicz

A

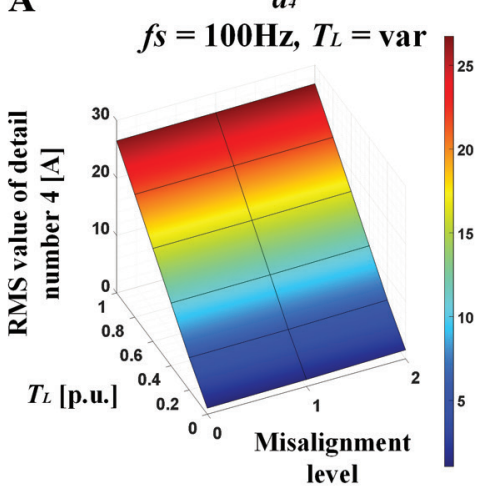

C

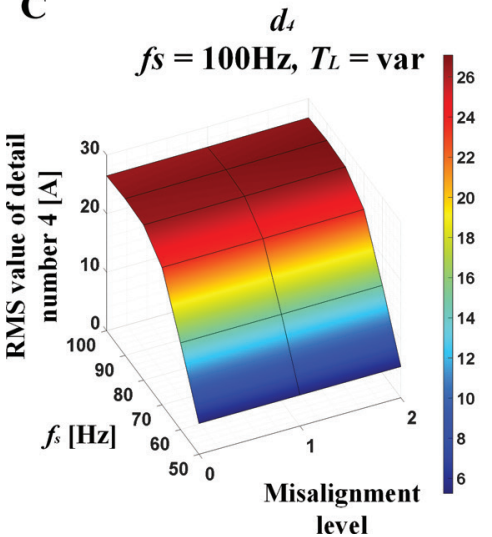

B

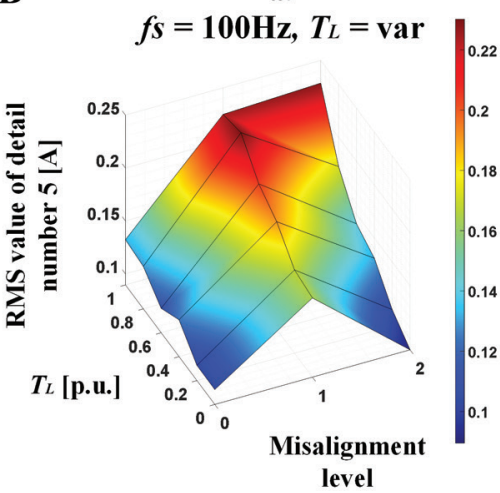

D

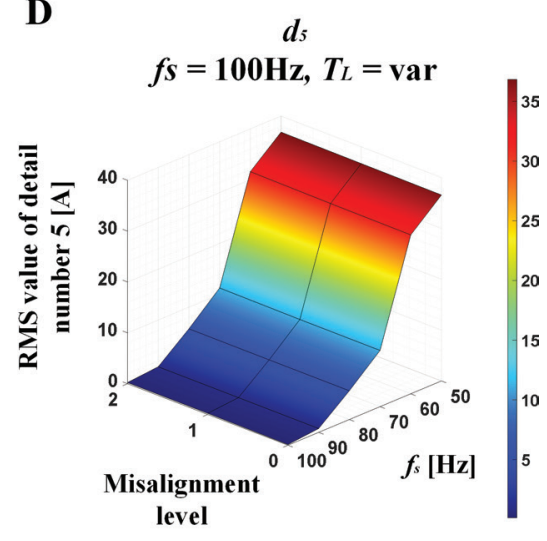

Fig. 12. (a, b) RMS values of the details number 4 and $5\left(f_{s}=10 \mathrm{~Hz}, T_{L}=\right.$ var) for the motor coaxial to the loading machine and for two levels of angular misalignment for various load torques and (c, d) influence of the supply voltage frequency and angular misalignment level on these values. RMS, root mean square.

$$
f s=100 \mathrm{~Hz}, T_{L}=T_{N}
$$
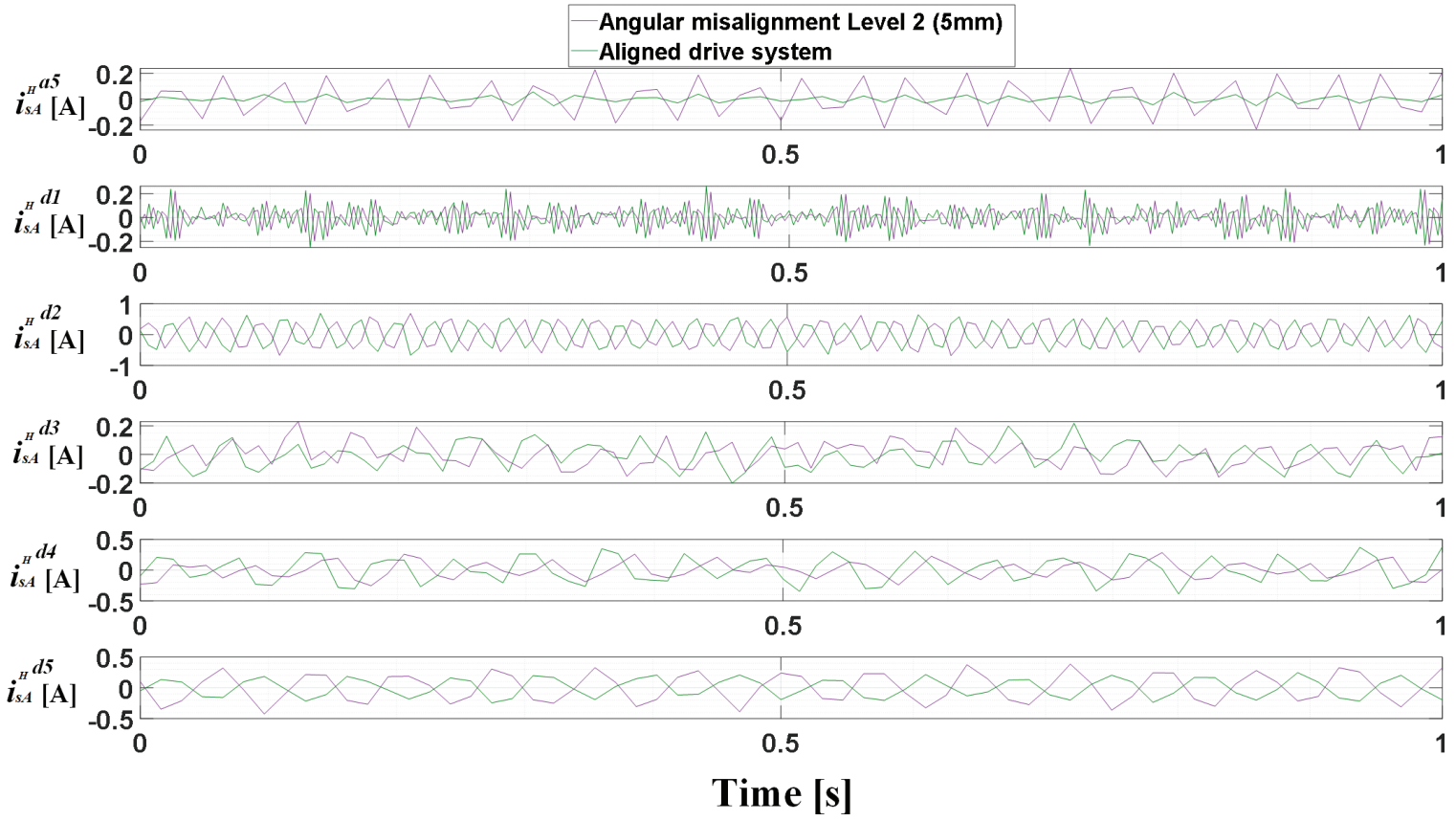

Fig. 13. Waveforms of approximations and details of the DWT of the stator phase current envelope for an aligned drive system and angular misalignment, operating at the rated power supply frequency $\left(f_{s}=100 \mathrm{~Hz}\right)$ and with rated load torque. DWT, discrete wavelet transform.

55 
A

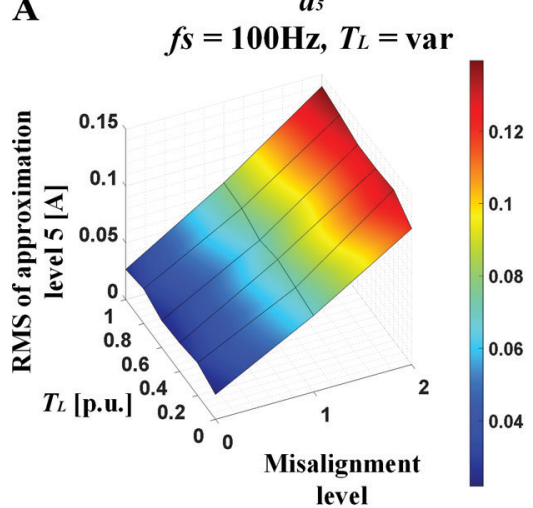

C

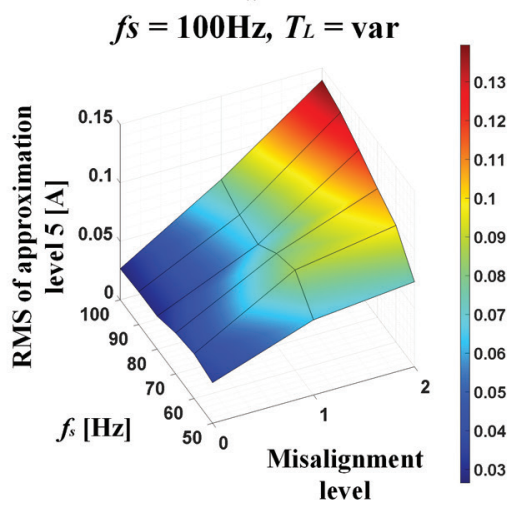

B $d s$

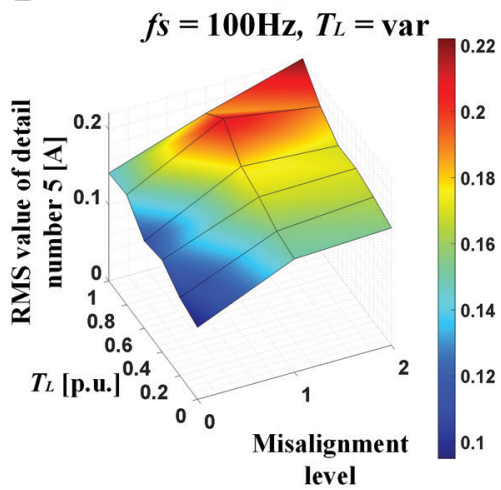

D

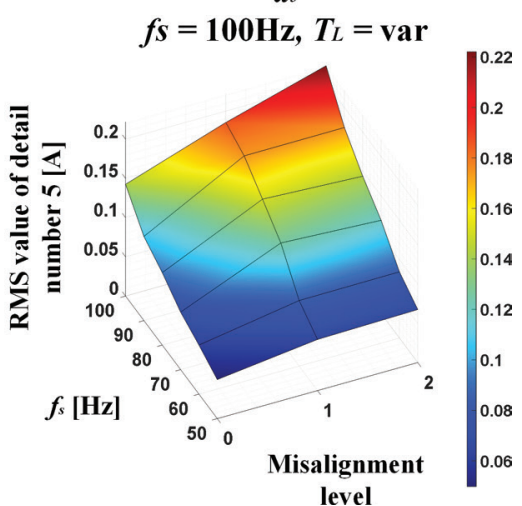

Fig. 14. (a, b) RMS values of the approximation Level 5 and detail number $5\left(f_{s}=100 \mathrm{~Hz}, T_{L}=\right.$ var) for the motor coaxial to the loading machine and for two levels of angular misalignment for various load torques and (c, d) influence of the supply voltage frequency and angular misalignment level on these values. RMS, root mean square.

$$
f s=100 \mathrm{~Hz}, T_{L}=T_{N}
$$

Angular misalignment Level 2 (5 $\mathrm{mm}$ ) Aligned drive system

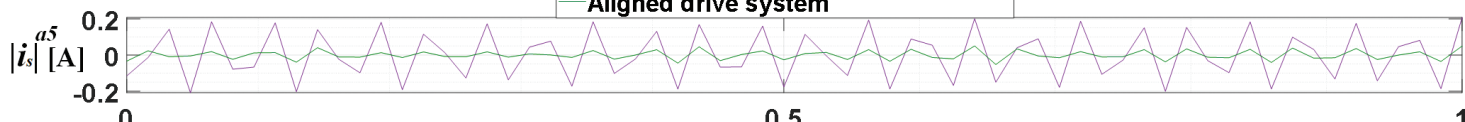

$$
-0.2
$$$$
0.5
$$

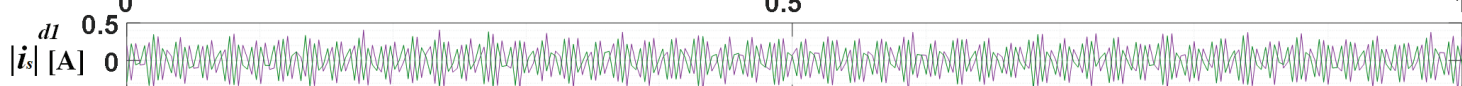

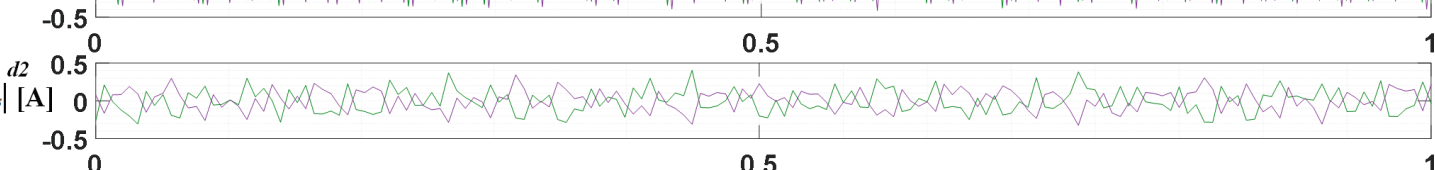

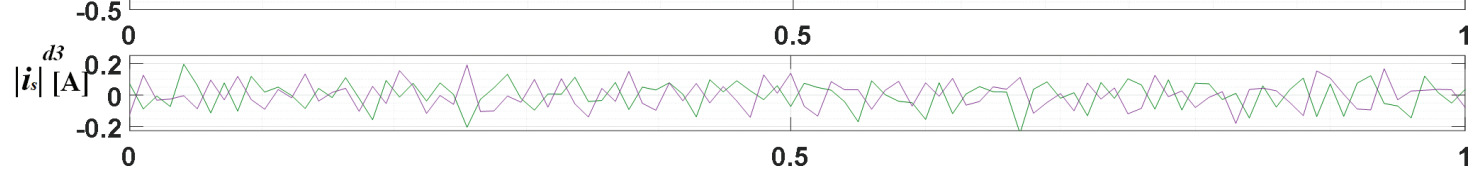

$\left|i_{s}\right|^{d 4}[\mathrm{~A}]_{-0.2}^{0.2} 0.5$

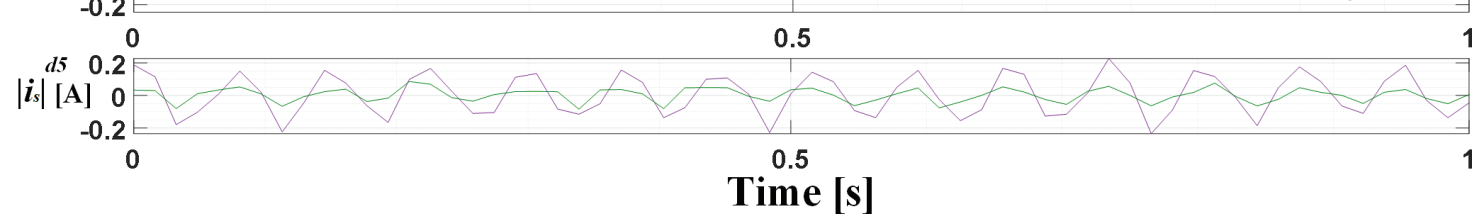

Fig. 15. Waveforms of approximations and details of the DWT of the stator phase current space vector module for an aligned drive system and angular misalignment, operating at the rated power supply frequency $\left(f_{s}=100 \mathrm{~Hz}\right)$ and with rated load torque. DWT, discrete wavelet transform. 
$\mathbf{A}$

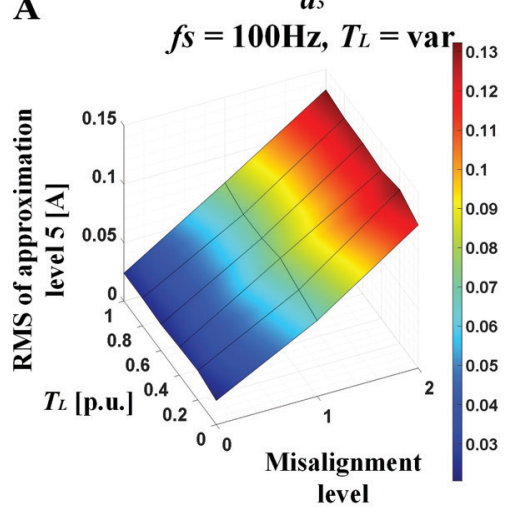

C

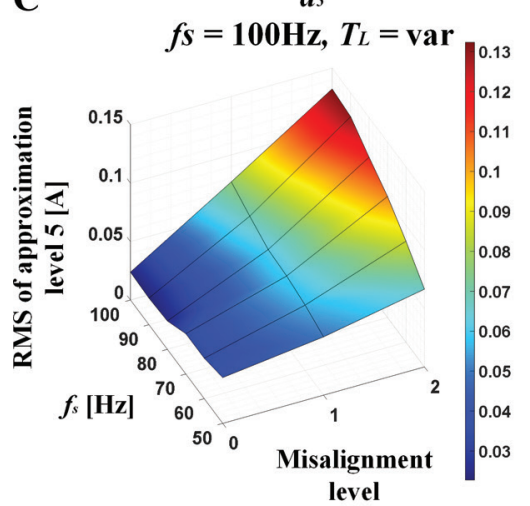

B

$d s$

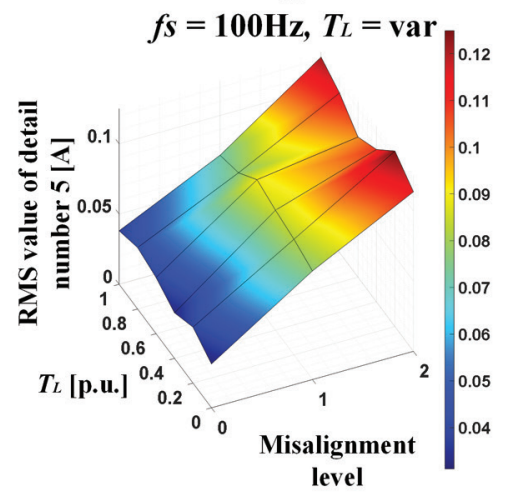

D

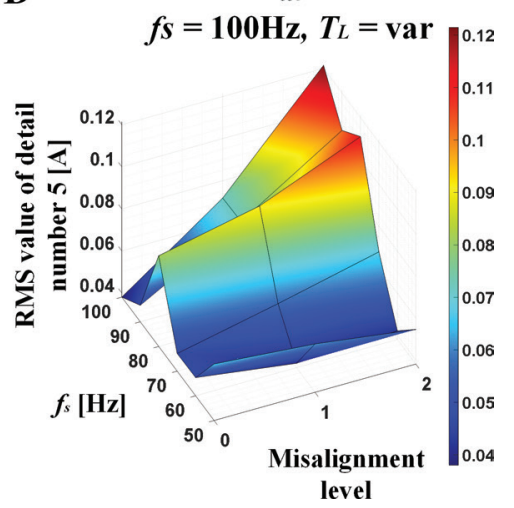

Fig. 16. (a, b) RMS values of the approximation Level 5 and detail number $5\left(f_{s}=100 \mathrm{~Hz}, T_{L}=\right.$ var) for the motor coaxial to the loading machine and for two levels of angular misalignment for various load torques and (c, d) influence of the supply voltage frequency and angular misalignment level on these values. RMS, root mean square.

number 5 , the band of which covers the value of the $f_{r}$ component in the spectrum of the stator current space vector module.

The influence of the load torque and misalignment level on the RMS values of $a_{5}$ and $d_{5}$ is shown in Figure $16(\mathrm{a}, \mathrm{b})$ and the influence of the fs is presented in Figure 16(c, d). As in the case of the DWT of the stator phase current envelope, the RMS values of $a_{5}$ and $d_{5}$ values increase with the increase in the degree of angular misalignment, but do not depend on the load torque. However, the influence of the supply voltage frequency changes is greater than in the case of DWT of current envelope.

\section{Summary}

The results of the research presented in this section show that the use of a DWT of the stator phase current gives results that are much worse when compared with the FFT of this signal. Nevertheless, the WT of the envelope and the space vector modulus allows for much better efficiency in detecting misalignment with a low sensitivity to changes in engine operating conditions, especially in the case of the DWT of the current envelope.

In Table 4, the RMS values of the DWT components that are most sensitive to misalignment for each of the discussed signal are grouped. Additionally, ratios of values for a given level of misalignment to values for aligned drive system are given in parentheses. Based on these values, it can be concluded that the changes of the DWT component that are most sensitive to the misalignment of the stator phase current $-d_{4}$ are definitely small and do not allow for detection of misalignment.

On the other hand, the increase in the approximate $a_{5}$ of the current envelope and the stator current space vector module is significant (from $300 \%$ to $555 \%$ in relation to the aligned system). Thus, it can be concluded that both of these analyses allow the extraction of effective fault indicators. Nevertheless, it should be remembered that in the 
Table 4. The amplitude values of DWT components for each of the discussed signal spectrums and ratios of values for a given level of misalignment to values for aligned drive system in parentheses

\begin{tabular}{lccc}
\hline & Stator phase current spectrum & Stator phase current envelope spectrum & Stator phase current space vector module spectrum \\
\hline \hline Misalignment level & $d_{4}$ & $a_{5}$ & $a_{5}$ \\
$T_{L}=0$ & & & \\
$0(0 \mathrm{~mm})$ & $1.058(1.00)$ & $0.022(1.00)$ & $0.021(1.00)$ \\
$1(2 \mathrm{~mm})$ & $1.201(1.13)$ & $0.071(3.07)$ & $0.065(3.15)$ \\
$2(5 \mathrm{~mm})$ & $1.542(1.46)$ & $0.133(5.46)$ & $0.122(5.94)$ \\
$T_{L}=0.6 T_{N}$ & & & \\
$0(0 \mathrm{~mm})$ & $16.18(1.00)$ & $0.024(1.00)$ & $0.022(1.00)$ \\
$1(2 \mathrm{~mm})$ & $16.24(1.00)$ & $0.070(2.97)$ & $0.072(3.21)$ \\
$2(5 \mathrm{~mm})$ & $16.45(1.02)$ & $0.130(5.49)$ & $0.129(5.76)$ \\
$T_{L}=T_{N}$ & & & $0.024(1.00)$ \\
$0(0 \mathrm{~mm})$ & $26.46(1.00)$ & $0.027(1.00)$ & $0.077(3.23)$ \\
$1(2 \mathrm{~mm})$ & $26.54(1.00)$ & $0.079(2.96)$ & $0.132(5.55)$ \\
$2(5 \mathrm{~mm})$ & $26.73(1.01)$ & $0.014(5.25)$ & \\
\hline
\end{tabular}

DWT, discrete wavelet transform.

Table 5. Standard deviation values of the DWT components RMS values for the entire tested load torque range and the ratio of its values for motor operation at rated load and without load (Misalignment level 2-5 mm).

\begin{tabular}{lccc}
\hline & $\begin{array}{c}\text { Stator phase current } \\
\text { spectrum }\end{array}$ & $\begin{array}{c}\text { Stator phase current } \\
\text { envelope spectrum }\end{array}$ & $\begin{array}{c}\text { Stator phase current space vector } \\
\text { module spectrum }\end{array}$ \\
\hline \hline$S$ & $d_{4}$ & $a_{5}$ & $a_{5}$ \\
$D W T_{\text {component for misalignment lv1 2 }}\left(T_{L}=T_{N}\right)$ & 9.5248 & 0.0067 & 0.0037 \\
\hline$D T_{\text {component for misalignment lv1 2 }}\left(T_{L}=0\right)$ & 17.3351 & 1.1651 & 1.0831 \\
\hline
\end{tabular}

DWT, discrete wavelet transform; RMS, root mean square.

case of DWT of the stator current envelope, it is enough to measure only one stator phase current and the values of $a_{5}$ depend less on the frequency of the supply voltage and do not depend on the load torque at all. To compare the impact of the load torque on the values of the described failure DWT components, the standard deviation for the entire tested load torque range was calculated in the same way as in Table 3 . These results, together with the ratio of the failure frequency amplitude value at rated load to the value without load, are grouped in Table 5.

On the basis of the results grouped in Table 5 it can be concluded that the $a_{5}$ stator phase current space vector module DWT component is the least load-dependent fault symptom. As already concluded from the analysis of surface plots presented below, the $d_{4}$ stator phase current DWT component depends strongly on the load torque value.

\section{Conclusions}

The article presents the results of research on detecting misalignment in drive systems with PMSMs. The results of experimental tests for the proposed methods of diagnosing this type of fault based on stator current signal are shown and discussed in detail. The presented experimental research results confirm the effectiveness of the application of the spectral analysis on the stator phase current, the stator phase current envelope, the stator phase current space vector module and the DWT of the stator current envelope and space vector module for the misalignment detection. The influence of the angular misalignment on the RMS value of the current, the shape of the phase current hodograph and the stator current space vector module is also discussed.

Moreover, this article presents information concerning the question of exactly which multiplicities of the characteristic failure frequency calculated according to Eq. (1) and Eq. (4) cause increase in the presence of 
misalignment. The influence of the load torque and the frequency of the power supply on these components was analysed and discussed in detail, which was not done in the existing literature. It was also proposed to use a DWT of the stator phase current envelope and space vector module and it has been shown that the monitoring of the values of individual approximations and details makes it possible to detect misalignment regardless of the value of the load torque and the power supply frequency. In addition, it has been proven that DWT of the envelope and monitoring of the value of the relevant components allows the detection of misalignment with the availability of measuring being restricted to one phase with high efficiency and in various motor operating conditions, which can be considered novel, and the wavelet transform of vibrations was most often proposed for the detection of this type of damage.

The confirmation of the effectiveness of the proposed methods discussed in the paper and their comparison may be the basis for the development of fault diagnostic and drives condition monitoring systems.

\section{Acknowledgements}

This research was funded by the National Science Center Poland under Grant No. 2017/27/B/ST7/00816.

\section{References}

Antonino-Daviu, J. and Popalent, P. (2018). Detection of Induction Motor Coupling Unbalanced and Misalignment via Advanced Transient Current Signature Analysis. 2018 XIII International Conference on Electrical Machines (ICEM), pp. 2359-2364.

Behera, D. P., Behera, R. and Naikan, V. N. (2014). Virtual Fault Simulation for Diagnosis of Shaft Misalignment of Rotating Machine. 2014 International Conference on Advances in Computing, Communications and Informatics (ICACCI), pp. 2476-2480.

Bossio, J. M., Bossio, G. R. and De Angelo, C. H. (2009). Angular Misalignment in Induction Motors with Flexible Coupling. 35 th Annual Conference of IEEE Industrial Electronics (IECON), pp. 1033-1038.

Chacon, J. L, Artigao, E. A., Kappatos, V., Asfis, G., Gan, T. H. and Balachandran, W. (2014). Shaft Angular Misalignment Detection using Acoustic Emission. Applied Acoustics, 85, pp. 12-22.

Ewert, P. and Musial, M. (2017). Detecting of Misalignment of the Drive Systems with Induction Motor Supplied by a Frequency Converter. Przegląd elektrotechniczny, 93(2), pp. 34-38.

Hang, J., Ding, S., Zhang, J., Cheng, M., Chen, W. and Wang, Q. (2016) Detection of Interturn ShortCircuit Fault for PMSM with Simple Fault Indicator. IEEE Transactions on Energy Conversion, 31(4), pp. 1697-1699.

Kim, K. H. (2011). Simple Online Fault Detecting Scheme for Short-Circuited Turn in a PMSM through Current Harmonic Monitoring. IEEE Transactions on Industrial Electronics, 58(1), pp. 2565-2568.
Liu, X., Liang, D., Du, J., Yu, Y., Yang, X. and Luo, Z. (2014). Effects Analysis of Misalignments on Dynamic Characteristics Test for Permanent Magnet Synchronous Motor. 2014 17th International Conference on Electrical Machines and Systems (ICEMS), pp. 1543-1547.

Olkkonen, J. T. (2011). Discrete Wavelet Transforms Theory and Applications, InTech, Rijeka, Croatia.

Piotrowski, J. (1995). Shaft Alignment Handbook. 2nd ed., Marcel Dekker Inc., New York.

Raj, V. P., Natarajan, K. and Girikumar, S. T. (2013). Induction Motor Fault Detection and Diagnosis by Vibration Analysis using MEMS Accelerometer. 2013 International Conference on Emerging Trends in Communication, Control, Signal Processing and Computing Applications (C2SPCA), pp. 1-6.

Saputra, P. P., Eliyani, M., Firmansyah, R. and Lastomo, D. (2019a). Haar and Symlet Discrete Wavelete Transform for Identification Misalignment on Three Phase Induction Motor Using Energy Level and Feature Extraction. Journal of Physics: Conference Series 1179 (ICCOMSET), pp. 1-6.

Saputra, P. P., Murdianto, F. D., Firmansyah, R. and Widarsono, K. (2019b). Combination of Quadratic Discrimination Analysis and Daubechis Wavelet for Classification Level of Misalignment on Induction Motor. 2019 International Symposium on Electronics and Smart Devices (ISESD), BadungBali, Indonesia, pp. 1-5.

Tarchala, G., Wolkiewicz, M. and Krzysztofiak, M. (2020). Diagnosis of Short-circuits in Induction Motor Stator Winding Using a Modified Park Transformation. Power Electronics and Drives, 5(41), pp. 123-133. 
Thomsons, W. T. and Culbert, I. (2017). Current Signature Analysis for Condition Monitoring of Cage Induction Motors. IEEE Press, Wiley, New Jersey.

Umbrajkaar, A., Krishnamoorthy, A. (2018). Shaft Misalignment Prediction On Basis Of Discrete Wavelet Transform. International Journal of Mechanical Engineering and Technology (IJMET), 9(7), pp. 336-344.

Usman, A., Joshi, B. M. and Rajpurohit B. S. (2017). Review of Fault Modeling Methods for Permanent Magnet Synchronous Motors and their Comparison. 2017 IEEE 11th International Symposium on Diagnostics for Electrical Machines, Power Electronics and Drives (SDEMPED), pp. 141-146.
Verma, A. K., Sarangi, S. and Kolekar, M. H. (2014). Experimental Investigation of Misalignment Effects on Rotor Shaft Vibration and on Stator Current Signature. Journal of Failure Analysis and Prevention, 14(2), pp. 125-138.

Wang, X., Wang, Z., Xu, Z., Cheng, M., Wang, W. and $\mathrm{Hu}$, Y. (2018). Fault Diagnosis and Tolerance of Dual Three-phase PMSM Drives. 2018 IEEE Energy Conversion Congress and Exposition (ECCE), pp. 325-330.

Zhang, J., Tounzi, A., Benabou, A. and Le Manach, Y. (2021). Detection of magnetization loss in a PMSM with Hilbert Huang transform applied to non-invasive search coil voltage. Mathematics and Computers in Simulation, 184, pp. 184-195. 